\title{
EARTHQUAKE RISK OVER TIME WINDOWS; DO PEOPLE BIAS RISK TO THE END OF AN INTERVAL?
}

\author{
BY \\ JUSTIN MOHAN VELLUPPILLAI
}

\begin{abstract}
A thesis
submitted to Victoria University of Wellington

in fulfilment of the requirements for the degree of

Master of Science in Psychology
\end{abstract}

Victoria University of Wellington

2013 


\section{Acknowledgements}

I wish to acknowledge a number of people who have contributed to this thesis either directly or indirectly. I feel very blessed to have been under the supervision of Professor John McClure, whose knowledge and expertise in this field have been as much appreciated as his fatherly concern and support. Dr Emma Hudson-Doyle made significant contributions through her previous research and valuable comments on my results. And lastly, my family and colleagues who believed in me and supported my efforts throughout, my wife Sarah, my parents Yogi and Ruth, and Catherine who did all the things that needed doing so I could give this study my undivided attention. Thank you. 


\begin{abstract}
Located on the edge of two tectonic plates, New Zealand has numerous fault lines and seismic risk across the whole country. The way this risk is communicated affects whether people prepare effectively or at all. Research has shown that perceptions of risk are affected by slight changes in wording, and that probabilities commonly reported by experts and media are often interpreted subjectively based on context. In the context of volcanoes, research has found that given a certain probability of a volcano in a specific time window, people perceive risk as higher in later time intervals within that window. The present study examines this pattern with regard to earthquakes and aftershocks in the New Zealand context. Participants in both Wellington $(N=102)$ and Christchurch $(N=98)$ were presented an expert statement of earthquake risk within a given time window in Wellington and aftershock risk in Christchurch, and asked to rate their perception of risk in specific intervals across the time window. For a Wellington earthquake, participants perceived risk as incrementally higher toward the end of the 50 year time window whereas for a Christchurch aftershock, risk perception increased slightly for the first three intervals of the 12 month time window. Likelihood of preparing was constant over the time windows, with Wellington citizens rating themselves more likely than Christchurch citizens to prepare for either an earthquake or aftershock, irrespective of current level of preparedness. These findings suggest that people view earthquakes as more likely later toward the end of a given time window and that they view aftershocks very differently to scientific predictions.
\end{abstract}




\section{Contents}

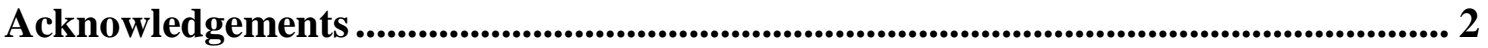

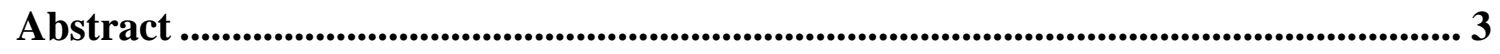

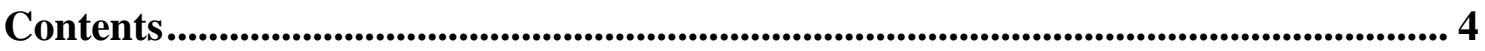

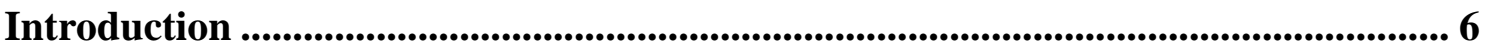

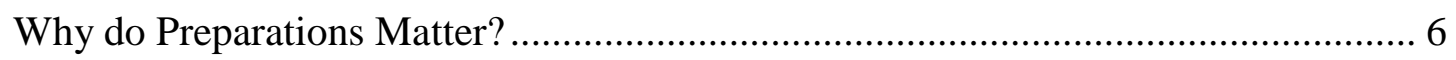

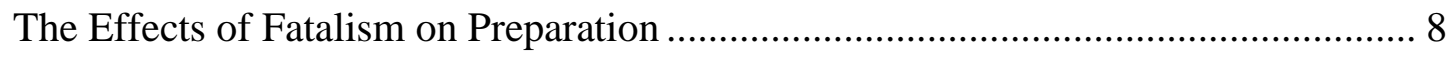

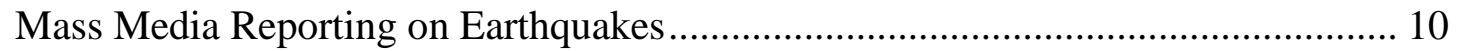

Psychological Factors in Probability Interpretation ................................................ 12

The Effects of Context and Base Rates on Probability Interpretation........................ 13

Previous Research on Time Window Probability Statements .................................. 14

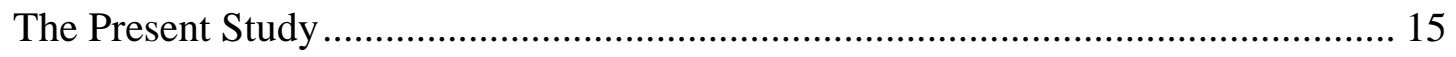

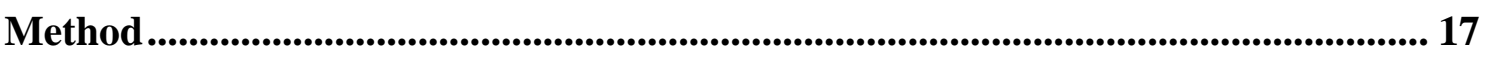

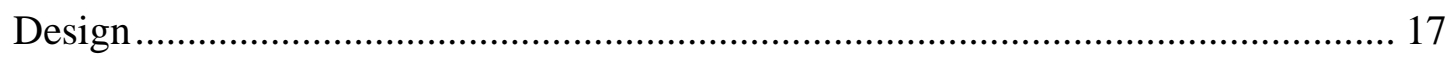

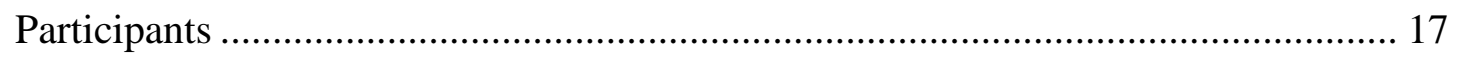

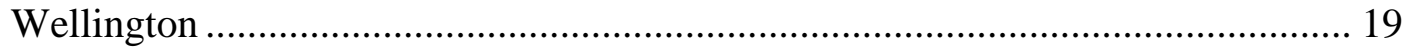

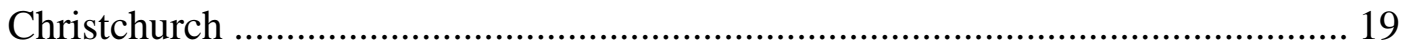

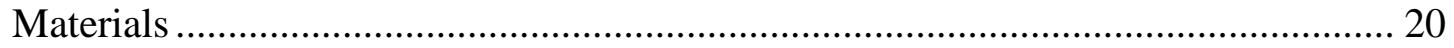

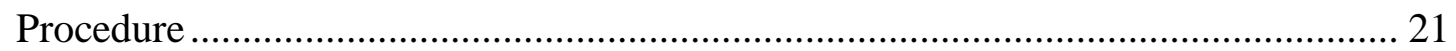

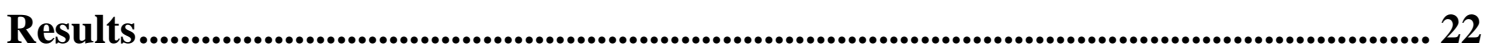

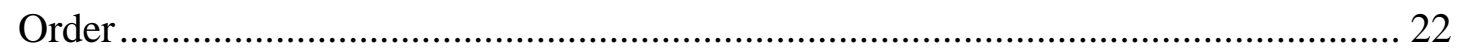

Judgements about an Earthquake in Wellington ................................................... 22

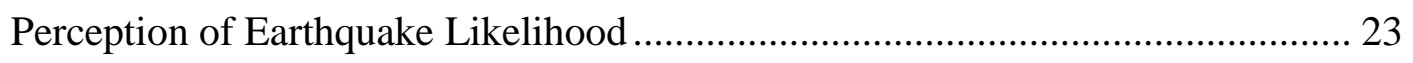

Likelihood of Increasing Preparedness for an Earthquake in Wellington.............. 25

Judgements about an Aftershock in Christchurch .................................................... 28

Perception of Aftershock Likelihood ................................................................... 29

Likelihood of Increasing Preparedness for Aftershocks in Christchurch............... 31 
Current Preparedness and Likelihood of Preparing Further 33

Discussion 35

Judgements about an Earthquake in Wellington ................................................... 37

Likelihood of an Earthquake Occurring ............................................................... 37

Likelihood of Increasing Preparedness for an Earthquake in Wellington.............. 38

Judgements about an Aftershock in Christchurch .................................................. 39

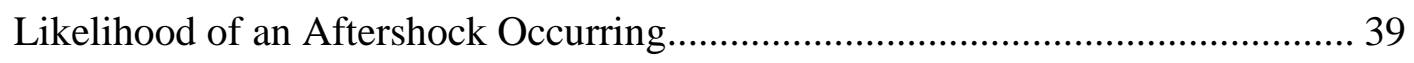

Likelihood of Increasing Preparedness for an Aftershock in Christchurch............ 41

Current Preparedness and Likelihood to Prepare Further ...................................... 42

Demographic Factors in Likelihood of Preparation ................................................ 43

Limitations of the Present Research and Future Directions ..................................... 45

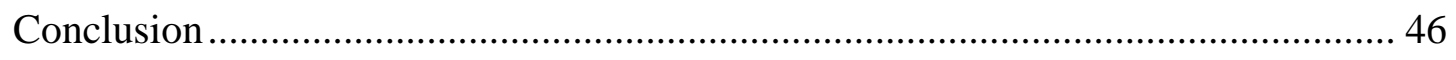

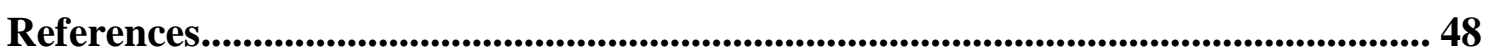

Appendix A: Questionnaires.......................................................................... 53 


\section{Introduction}

Earthquakes and aftershocks in Canterbury, New Zealand in 2010 and 2011 have highlighted the importance of preparations in minimizing damage to property and loss of life. On September 4, 2010 an earthquake measuring 7.1 on the Richter scale struck in Darfield, a small town located $45 \mathrm{~km}$ from Christchurch. Just months later on February 22, 2011, a shallow aftershock measuring 6.3 on the Richter scale struck in Lyttleton, just $12 \mathrm{~km}$ from the Christchurch central business district (CBD). The second event directly resulted in the loss of 185 lives, mainly through the collapse of two buildings in the CBD, and caused significant damage to Christchurch's buildings and infrastructure. At the time this study was run, 18 months had passed since the February, 2011 earthquake, and the city was still experiencing regular aftershocks. These were expected to continue for some time (GeoNet, 2013). The salience of earthquakes in the context of these recent events created an opportune time to inform and educate the public, and review government policy around earthquake preparation and building standards.

\section{Why do Preparations Matter?}

The extent to which people prepare for earthquakes has a significant effect on damage and survival outcomes (Lindell \& Whitney, 2000; Smith, 1993). Civil Defence emergency management in New Zealand recommends preparations for every household such as a survival kit containing water, a torch, radio, and food items. Basic preparations such as fastening items, stacking shelves correctly, and securing furniture reduce damage to property during an earthquake (Paton, 2003; Smith, 1993; Turner, Nigg, \& Heller Paz, 1986). A comparison of recent earthquakes in Haiti, New Zealand, 
Chile and Japan, with their significantly different levels of building code stringency and adherence, and accordant building damage and loss of life suffered suggests the important contribution of building design to earthquake outcomes. More damage was sustained by buildings in Haiti in a smaller earthquake than larger earthquakes in countries such as Chile and Japan with better building codes and building code adherence. These earthquakes illustrate the finding that a large portion of damage during an earthquake can be attributed to building design, rather than simply earthquake magnitude (Smith, 1993). Further, attaching brackets to computers was found to be a key determinant of survival of businesses after the 1989 San Francisco earthquake (McClure, Allen, \& Walkey, 2001; Smith, 1993). With the increasing role of computers in business since 1989 this is likely even more significant in more recent events. Survival preparation actions are also considered important by experts for the 72 hours immediately following an earthquake when emergency services may be stretched and water and food supplies may be cut off (Russell, Goltz, \& Bourque, 1995). While earthquake occurrence and magnitude is outside our control and is somewhat unpredictable, earthquake damage and loss is much reduced by preparation.

Despite the effectiveness of earthquake preparation in mitigating the risk of damage and loss of life, studies have found that people often do not make basic preparations for earthquakes (Lindell \& Perry, 2000; Rüstemli \& Karanci, 1999; Spittal, McClure, Siegert, \& Walkey, 2008). Turner et al. (1986) surveyed earthquake preparedness in California and found that even easily accessible, affordable preparations had been neglected by the majority of households. The same participants reported awareness of the high earthquake risk in their area, yet more than $25 \%$ did not have a working flashlight, $46 \%$ had no first aid kit, and $45 \%$ had no radio. Of those that had 
these survival preparations, many reported it was by coincidence, for reasons unrelated to earthquake preparation.

There are many factors affecting likelihood of preparing for earthquakes, and these must be managed effectively to ensure best voluntary preparation outcomes. These factors include the way that media reports depict earthquakes, the types of messages and framing of the information in those messages, people's judgements about earthquakes, fatalism or helplessness about earthquakes and damage by association, and attributions for damage. Preparation may also be affected by the tendency to delay preparation actions - a form of procrastination (Steel, 2007). In light of these factors, it is important that messages from the media and experts such as scientists, engineers and seismologists are both well communicated and correctly interpreted. Earthquakes are a low frequency event, and the belief that they are unlikely to be experienced in one's own lifetime, let alone the near future, coupled with a sense of their uncontrollability, creates conditions conducive to delaying preparations.

\section{The Effects of Fatalism on Preparation}

There are a number of suggestions as to other causes of this lack of earthquake preparations. Turner et al. (1986) suggest that fatalism plays a role. In their study, many participants indicated strong agreement with four items measuring fatalism, such as "The way I look at it, nothing is going to help if there were an earthquake". Fatalism is a similar state to learned helplessness (Seligman, 1972), where a lack of control in one setting generalises to a perceived helplessness in another situation. Learned helplessness leads to inaction in situations where outcomes can easily be affected (McClure, Walkey, \& Allen, 1999; Strickland, 1989). In regard to earthquake preparedness, learned 
helplessness manifests as perceived helplessness to affect earthquake outcomes, generalised from a lack of control over earthquake occurrence. The lack of control over earthquake occurrence is real, whereas lack of control over the outcomes of building damage and personal injury is not - preparations such as building design, fastening items and the way shelves are stacked have an effect on these outcomes (Smith, 1993; Turner et al., 1986).

Fatalism may lead people to interpret the damage to buildings in earthquakes as uncontrollable (McClure et al., 1999). Unless the distinctive features of damaged buildings such as building age, design and adherence to codes are made apparent, people may attribute damage to earthquake magnitude and minimize the importance of the controllable factor - building design (McClure et al., 2001; McClure \& Williams, 1996). It is possible in this way to see the right information but learn the wrong lessons.

Studies have examined factors contributing to fatalism and learned helplessness. Messages received about earthquakes can contain certain types of information that affect people's judgements about earthquakes. McClure et al. (2001) examined the effect of messages containing information about the distinctiveness of damage to certain types of buildings and similarities in the effects of other earthquakes on similar buildings (termed consensus and consistency information respectively). They found that these messages lead to attributions to building design, a controllable cause of damage. Related research showed that messages containing rate-based information (describing the types of buildings that suffered most damage) resulted in less fatalistic attributions than instance-based information about specific buildings suffering damage (McClure, Sutton, \& Sibley, 2007). 
This finding was expanded by Cowan, McClure, and Wilson (2002), who compared newspaper articles published in the weeks immediately after and one year after the 1995 Kobe, Japan earthquake. 'Week-after' articles contained more fatalistic messages of widespread destruction and instance-based reports of damage whereas 'year-after' reports were less fatalistic and more informative about the type of buildings suffering most damage. Presenting these different types of article to participants, Cowan et al. found that people reading the week-after reports showed more fatalism than those reading the year-after reports. The type, framing and information contained in messages about earthquakes thus have an impact on perceptions about these earthquakes and the resulting damage.

\section{Mass Media Reporting on Earthquakes}

Mass media reports provide an important source of information about earthquakes. Following major events, media communications are the primary source of information upon which many people rely (Cowan et al., 2002; Piotrowski \& Armstrong, 1998). This has the positive effect of the dissemination of important information, but it can also have negative effects. The type of messages conveyed by the media are known to frame events in certain ways (Vasterman, Yzermans, \& Dirkzwager, 2005). Media tend to focus on the sensational aspects of a natural disaster, including loss of life, and damage to buildings and infrastructure, rather than communicating the types of distinctive damage messages that promote preparation. News reporting often relies on eye-witness reports rather than stating the opinions and knowledge of experts (Walters \& Hornig, 1993). Mass media reporting plays an 
important role in the communication of natural disasters, and contributes to shaping people's judgements about risk.

As noted earlier, Cowan et al. (2002) demonstrated the effects of different types of statements reported in week-after and year-after reports on the Kobe earthquake on judgements about earthquakes. The media also report experts' statements of earthquake risk. Statements by scientists and engineers often include descriptions of earthquake risk and building design features. Research has found that the source of earthquake messages, whether expert or non-expert, has less effect on fatalism than the type of message (McClure et al., 2007). The way expert opinions are reported usually involves less of the fatalism seen in media reports, and more statistical data such as probabilities of an event. These are revised periodically and can include statements such as "there is a $33 \%$ chance of a magnitude 5 or higher earthquake in the next 12 months". However, the way this information is perceived and affects citizens' judgements about earthquake may not always be as intended by the expert (Doyle, Johnston, McClure, \& Paton, 2011; Patt \& Schrag, 2003).

Media reporting is influential in people's judgements about natural disasters and a key source of information about events. The way expert statements are framed affects judgements about earthquakes. For example, Doyle et al. (2011) found the use of the words "within" and "in" in statements such as "within a week" led to different judgements about volcano risk. Slight changes to framing are important, as are the probabilities themselves. 


\section{Psychological Factors in Probability Interpretation}

There is a wide body of literature describing nuances in lay interpretations of statistical probabilities, such as confusion between conditional and joint probabilities (Pollatsek, Well, Konold, Hardiman, \& Cobb, 1987), the base rate fallacy, or ignoring base rates over specific indicators (Bar-Hillel, 1980), filtering statistical statements through contextual information or theories (Windschitl \& Weber, 1999) and biasing toward certain probabilities (Kahneman \& Tversky, 1979). These effects are significant in the communication of earthquake risk.

Experts include many sources of information in formulating their estimations of risk (Doyle, McClure, Johnston, \& Paton, 2012). These are often condensed down to a single sentence statement of risk in media reports. There is evidence that readers of these risk statements narrow these statements down even further for very small or large probabilities, into a binary judgement of risk - it will either happen or not (Patt \& Schrag, 2003). When framed using statements of probability such as "likely" or "unlikely" instead of percentages, research shows that there is a disparity between different people as to what percentages these probabilistic statements translate to (Dhami \& Wallsten, 2005; Karelitz \& Budescu, 2004; Wallsten, Fillenbaum, \& Cox, 1986; Weber, 1994; Weber \& Hilton, 1990). The range of percentage judgements for these probability statements is lower for statements translating to approximately $0,0.5$ and 1 probability (Kahneman \& Tversky, 1979). However, it is not just the interpretation of probabilistic statements that suffers these subjective effects. 


\section{The Effects of Context and Base Rates on Probability Interpretation}

Windschitl and Weber (1999) found that even percentage probabilities are interpreted on the basis of their context. Context has been identified as another important factor contributing to perception of probabilities and probability phrases (Weber \& Hilton, 1990). Real world knowledge provides context in which probabilities are understood. Vague probability statements such as "likely", "possible" and "probable" are interpreted by citizens in the context of the base rates of events to which they refer (Wallsten et al., 1986). Base rates refer to the normal likelihood of a certain event. When a probability is given about such an event occurring, people perceive the event's likelihood as a function of both the event's base rate likelihood of occurring and the probability given. This contextual interpretation has been found for both probability statements and numerical probabilities. For example, when presented with the probability statements "there is a $30 \%$ chance of rain in Madrid" and "there is a $30 \%$ chance of rain in London", rain is perceived as more likely in the latter case due to the higher base rate of rain in London than Madrid, as rain is more frequent in London than Madrid (Patt \& Schrag, 2003).

The base rate concept applies slightly differently to a seismic event than to the single events previously studied, such as chance of rain or various medical conditions. Experts in seismology have indicated that aftershocks in Christchurch are expected to decrease in likelihood over time (GeoNet, 2013), giving a longitudinal base rate rather than a snapshot. Thus, if citizens' views reflect the scientific predictions, the probability of an aftershock one year after an earthquake would likely be perceived by citizens as higher than the probability of an aftershock ten years after an earthquake. Conversely, citizens' perceptions of the probability of an earthquake would be expected to match 
their base rate perceptions of the likelihood of an earthquake over time, whether increasing or decreasing.

In a similar way to base rates, the severity of an event contributes differentially for positive and negative events to the perceived likelihood of that event. Weber and Hilton (1990) presented a sample of college students with medical scenarios with outcomes that differed in severity. Measuring perceptions of the same probability statements about the likelihood of different scenarios, the study showed that outcomes with greater severity were rated as more probable. Thus, context effects such as base rates and the severity of an event are known to affect the interpretation of probabilistic statements, which has implications for how expert statements of risk are communicated through media.

\section{Previous Research on Time Window Probability Statements}

Doyle et al. (2011) showed that both experts and non-experts misinterpret probabilities relating to risk of natural disasters. In an online questionnaire, scientists and lay persons were presented with expert statements of volcano risk. These statements contained a percentage probability of a volcanic eruption in the next ten years, such as "35-45\% within the next 3 days". Participants then rated their perception of the likelihood of an eruption at various stages within and immediately after that time window. Doyle et al. (2011) found that both scientists and laypersons rated a volcano as more likely later in these time windows (i.e., more likely on Wednesday than Monday), despite the probabilities given by the scientists presenting no actual difference in likelihood. In understanding experts' probabilistic statements, participants discounted immediate over delayed risk. 
In a second study, Doyle et al. (2012) found the same effect for time windows of three to five days in length. Despite no statistical difference in the likelihood of a volcano on any of the days within the stated period, both scientists and non-scientists rated their perceptions of the likelihood of a volcano as greater in later days within the time windows. Doyle et al. (2012) suggested that base rates and the overlaying of real world knowledge were possible explanations for the finding. Whether or not these base rates are correct, the lay theory that volcanoes increase in pressure over time was overlaid on the experts' estimates of risk, resulting in an upward trend in perceptions of volcano risk within the time window.

\section{The Present Study}

Doyle et al. (2011) suggested that their findings on volcanic eruptions may also apply to experts' probabilistic statements about earthquake likelihood. Communications about volcano and earthquake risk in New Zealand are similar in that estimates of probability of an event within a certain time frame are commonly reported by experts and mass media. The media reports statements by scientists such as "the likelihood of a magnitude 7 earthquake within $100 \mathrm{~km}$ of Wellington is $90 \%$ in the next 50 years" (Van Dissen et al., 2010). However, the way such phrases are perceived by the public and their resulting perception of risk within the given timeframe has not been examined in the context of seismic activity. Volcanoes and earthquakes are also different in that the underlying mechanisms that determine changes in likelihood of each event over time (or base rates) differ for each, and lay theories are likely to reflect this pattern. The present study aimed to apply the design of Doyle et al.'s (2011) experiment to earthquakes and aftershocks in New Zealand. 
New Zealand is on the edge of the Australian and Pacific tectonic plates, making it prone to earthquakes. Wellington has been identified as a city of particular risk, a fact that has been frequently reported by media. Christchurch has recently experienced significant earthquakes including a 7.1 magnitude (on the Richter scale) initial earthquake in September, 2010 and a damaging 6.3 earthquake in February, 2011. Aftershocks were ongoing at the time of this study. These two cities are therefore ideal settings for a comparison of judgements of earthquakes and aftershocks (McClure, Wills, Johnston, \& Recker, 2011). It was hypothesised that perceptions would differ for time windows in Wellington (earthquakes) and Christchurch (aftershocks). A major earthquake is considered moderately likely in the Wellington region in the near to intermediate future (Van Dissen et al., 2010), and thus it was expected that perceptions of likelihood of a major earthquake would trend toward increasing over time. In contrast, the frequency of aftershocks decreases over time after a major earthquake, so it was predicted that judgements of aftershock likelihood would be lower in later intervals within the time window. The view of volcanoes as increasing in pressure over time is thus more akin to earthquakes than aftershocks. It was therefore hypothesised that despite the significantly longer period for earthquake likelihood, judgements about earthquake likelihood would mirror Doyle et al.'s (2011) finding of higher judgements of likelihood toward the end of the time window more closely than judgements about aftershocks.

The present study also examined intentions to make further preparations for seismic events. Previous research has found a weak or non-existent relationship between perceptions of the likelihood of an earthquake and subsequent preparedness, whereas other factors such as home ownership and age are related to preparedness 
(McClure et al., 1999; Spittal et al., 2008). I predicted that participant ratings of their likelihood of making further preparations for an earthquake and aftershock would increase over the time windows due to procrastination (Steel, 2007).

\section{Method}

\section{Design}

Participants were presented with scientists' estimates of earthquake and aftershock risk for specified time windows. Participants rated the likelihood of that event, and their likelihood of making preparations, inside time intervals within that window. There were six ten-year intervals within a 60 year period for an earthquake in Wellington, and seven two-month intervals within a 14 month time window for an aftershock in Christchurch. Each questionnaire consisted of two parts; Wellington earthquakes and Christchurch aftershocks. Every second participant was given the Christchurch aftershock part first, the others were given the Wellington earthquake part first, to control for any order effects.

\section{Participants}

The participants included members of the public in both Christchurch and Wellington. There were 103 questionnaires completed in Wellington, and 101 in Christchurch. Four were excluded (three from Christchurch and one from Wellington) on the basis of participant collusion, and inability to adequately understand the questions. A total of 98 participants in Christchurch completed the questionnaire and were included in the study, 49 completing the Wellington earthquake questions first and 49 completing the Christchurch aftershock questions first. In Wellington, 102 
participants completed the questionnaire and were included in the study, 51 completing the Wellington earthquake questions first and 51 completing the Christchurch aftershock questions first.

Table 1. Demographic frequencies: Age group, gender, current preparedness, home ownership, previous earthquake experience, and concern about statements of risk.

\begin{tabular}{|c|c|c|}
\hline & Wellington & Christchurch \\
\hline \multicolumn{3}{|l|}{ Age Group } \\
\hline$<20$ & 15 & 9 \\
\hline $21-30$ & 24 & 22 \\
\hline $31-40$ & 19 & 15 \\
\hline $41-50$ & 22 & 17 \\
\hline $51-60$ & 15 & 13 \\
\hline $61+$ & 7 & 20 \\
\hline \multicolumn{3}{|l|}{ Gender } \\
\hline Male & 29 & 42 \\
\hline Female & 73 & 55 \\
\hline \multicolumn{3}{|l|}{ Preparedness } \\
\hline 1 (lowest) & 10 & 5 \\
\hline 2 & 11 & 12 \\
\hline 3 & 14 & 10 \\
\hline 4 & 20 & 18 \\
\hline 5 & 26 & 18 \\
\hline 6 & 14 & 15 \\
\hline 7 (highest) & 6 & 20 \\
\hline \multicolumn{3}{|l|}{ Home owner } \\
\hline Yes & 56 & 39 \\
\hline No & 46 & 58 \\
\hline \multicolumn{3}{|l|}{ Experienced previous quakes } \\
\hline Yes & 8 & 24 \\
\hline No & 93 & 72 \\
\hline \multicolumn{3}{|l|}{ Concerned about Wellington } \\
\hline Yes & 14 & 62 \\
\hline No & 87 & 32 \\
\hline \multicolumn{3}{|l|}{ Concerned about Christchurch } \\
\hline Yes & 18 & 66 \\
\hline No & 83 & 29 \\
\hline
\end{tabular}




\section{Wellington}

The study included 103 participants from Wellington. One was excluded due to inadequate understanding of the questionnaire. Of these, 52 answered the Wellington earthquake side of the questionnaire as page one, and 51 answered the Christchurch aftershock side as page one. Table 1 shows the demographic information for these participants in detail. There were 87 participants indicating that the scientist's estimate of earthquake risk in Wellington concerned them, and 83 indicating that the estimate of aftershock risk in Christchurch concerned them. The mean rating of current preparedness for an earthquake was $M=4.07(S D=1.68)$. Thirty different suburbs were indicated for participants' residence, representing a good spread around the Wellington area. Most participants had not experienced either of the Canterbury earthquakes in September, 2010 or February, $2011(N=94) .70 .9 \%$ of participants were female $(N=73)$ and $29.1 \%$ were male $(N=30)$.

\section{Christchurch}

101 participants were included in Christchurch. Three were excluded due to collaboration, English difficulties or incomplete responses. Table 1 details the demographic information about participants in Wellington. A total of 51 participants answered the Wellington earthquake questions first, and 50 answered the Christchurch aftershock questions first. There were 63 participants indicating that the scientist's estimate of earthquake risk in Wellington concerned them, and 67 indicating that the estimate of aftershock risk in Christchurch concerned them. The mean rating of current preparedness for an earthquake was $M=4.57(S D=1.85)$. Participants represented 41 different suburbs as place of residence. There were 74 participants $(74.7 \%)$ in the 
Christchurch sample who had experienced at least one of the Canterbury earthquakes in September, 2010 and February, 2011. In Christchurch 57\% of participants were female $(N=57)$ compared with $43 \%$ male $(N=43)$.

\section{Materials}

The questionnaire was a single, double-sided sheet of paper, with the Christchurch aftershock questions on one side and the Wellington earthquake questions on the other (see Appendix A). Demographic questions were included at the end of the questionnaire, on the second page. There were two versions of the questionnaire, differing in the order of the aftershock and earthquake questions. There were three questions for each of the Wellington earthquake and Christchurch aftershock sections of the questionnaire.

The Wellington page of the questionnaire started with a scientist's estimate of earthquake risk, stated as "Leading NZ scientists state that the likelihood of a magnitude 7 earthquake occurring within $100 \mathrm{~km}$ of Wellington is $90 \%$ in the next 50 years"1 (Davey \& Shephard, 1995). The first question was “Does this concern you?", which was included to ensure participants actually read the statement. The second question asked participants to rate the likelihood of such an earthquake in six time intervals, 0-10 years, 10-20 years, 20-30 years, 40-50 years and 50-60 years. The likelihood of such an earthquake in Wellington in each interval was rated on a 7-point Likert scale, from 1 (extremely unlikely) to 7 (virtually certain). For the third question, participants rated their likelihood of making additional preparations. The same time intervals and 7-point

\footnotetext{
${ }^{1}$ Note: This prediction was revised for Wellington by Russ Van Dissen, GNS Science in August, 2012.
} 
Likert scales were used. For the second and third questions, space was given for any comments participants wished to optionally add.

The Christchurch aftershock page of the questionnaire presented a scientist's estimate of aftershock risk, "Leading NZ scientists state that the likelihood of a 5.5 5.9 magnitude aftershock in Christchurch is $33 \%$ in the next 12 months." This statement was published on the GeoNet website, a publicly available source of information provided by the Earthquake Commission and GNS Science (GeoNet, 2013). The same questions were included as for the Wellington page, with intervals 0-2 months, 2-4 months, 4-6 months, 6-8 months, 8-10 months, 10-12 months and 12-14 months (one more interval than the Wellington questions).

The Wellington earthquake and Christchurch aftershock questions were followed by an additional question "How prepared do you feel you are now for an earthquake?", and questions to gather demographic information - house ownership, age bracket, gender, suburb, and whether the participant was in Christchurch for either the September or February earthquakes.

\section{Procedure}

The Christchurch part of the study was run first, 18 months after the February, 2011 Christchurch earthquake. A stall was set up at the Sunday market in Riccarton, Christchurch, where attendees voluntarily participated in the study. Questionnaires were completed in the presence of the researcher who was available to answer any questions as required. Half the participants started with the Wellington earthquake questions, the other half started with the Christchurch aftershock questions. Order was alternated so that no two participants arriving consecutively were given the same questionnaire order. 
The Wellington part of the study was run one week after the Christchurch study. A stall was set up at the Wellington Sunday market outside Te Papa museum. Participation was voluntary, and the order was alternated between consecutive participants, as with the Christchurch part of the study. The researcher was available to answer any questions. All participants in the study were offered a block of chocolate in appreciation of their participation.

\section{Results}

\section{Order}

The Christchurch and Wellington parts of the questionnaire were completed in opposite order by half the participants. An analysis of variance (ANOVA) showed no significant effects based on order for any of the questions.

\section{Judgements about an Earthquake in Wellington}

The mean ratings of earthquake likelihood in Wellington and likelihood of preparing more are shown in Figure 1. A 2 (Measure: earthquake likelihood and preparation) x 6 (Interval) x 2 (Participant location) MANOVA was performed, with Measure and Interval repeated measures variables and Participant location a between subjects variable.

A main effect was found for Measure, $F(1,175)=48.76, p<.001, \eta^{2}=.22$, showing that participants rated their likelihood of preparing higher $(M=5.07)$ than they rated the likelihood of an earthquake occurring $(M=4.23)$. There was also a main effect for Interval, $F(5,171)=6.32, p<.001, \eta^{2}=.16$. There was an interaction between 
Measure and Interval, $F(5,171)=25.53, p<.001, \eta^{2}=.22$. Because of this interaction, separate analyses were performed on the earthquake likelihood and preparation scales.

Figure 1. Mean ratings of earthquake likelihood and preparation in Wellington for each 10 year interval.

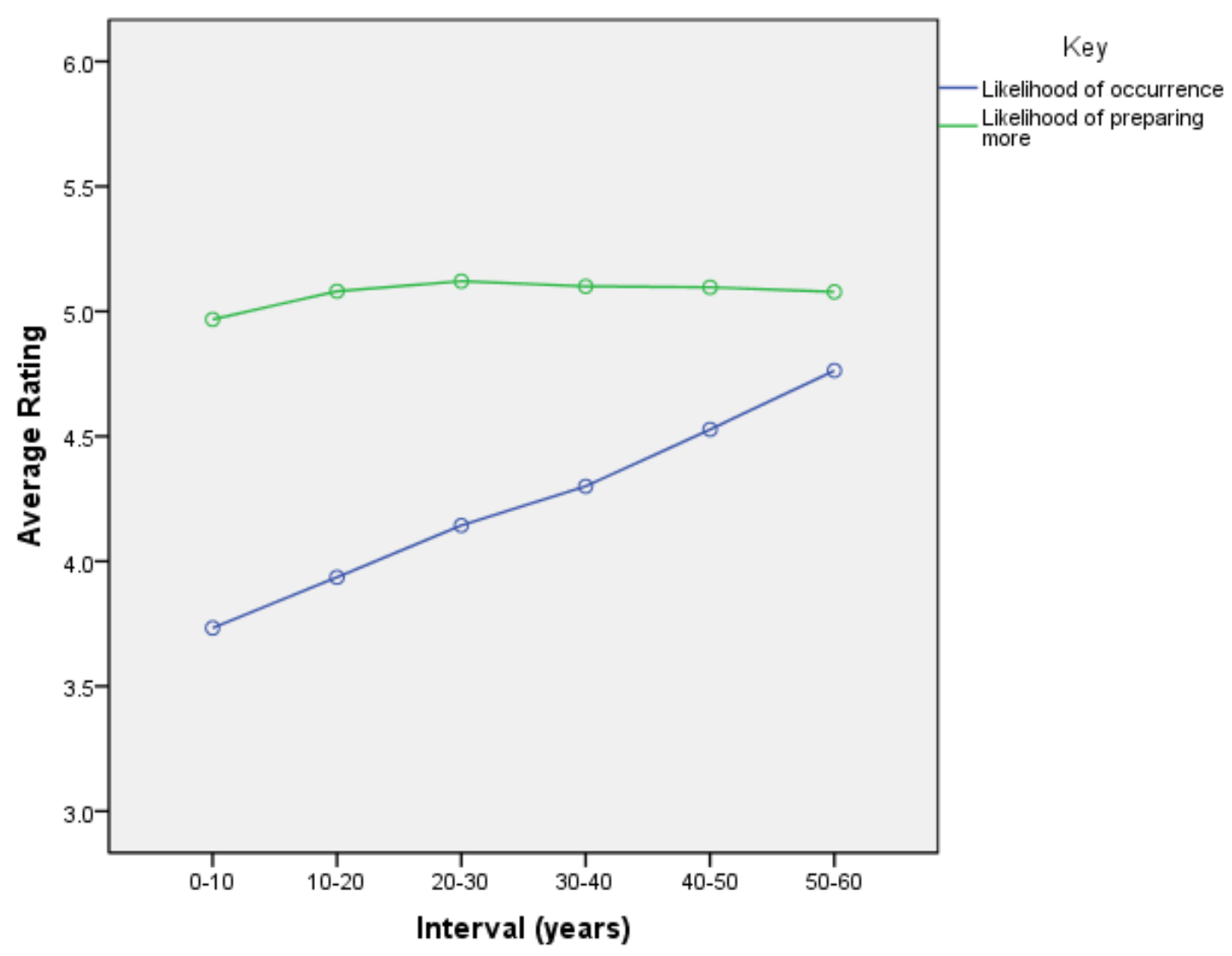

\section{Perception of Earthquake Likelihood}

The mean rating of likelihood of an earthquake in Wellington in each of the tenyear time intervals is shown in Figure 2. A 2 (Participant location) x 6 (Interval) x 2 (Concerned about Wellington earthquake) x 2 (Home ownership) x 2 (Gender) x 6 (Age group) ANOVA was performed on ratings of earthquake likelihood, with Interval a repeated measures variable and the other variables between subjects. A main effect was 
found for Interval, $F(5,179)=18.18, p<0.001, \eta^{2}=.13$, confirming that participants rated the likelihood of an earthquake higher in later time intervals. Subsequent $t$-tests showed that ratings increased for each successive interval, all $p<.001$.

Figure 2. Mean ratings of likelihood of a Wellington earthquake for each time interval.

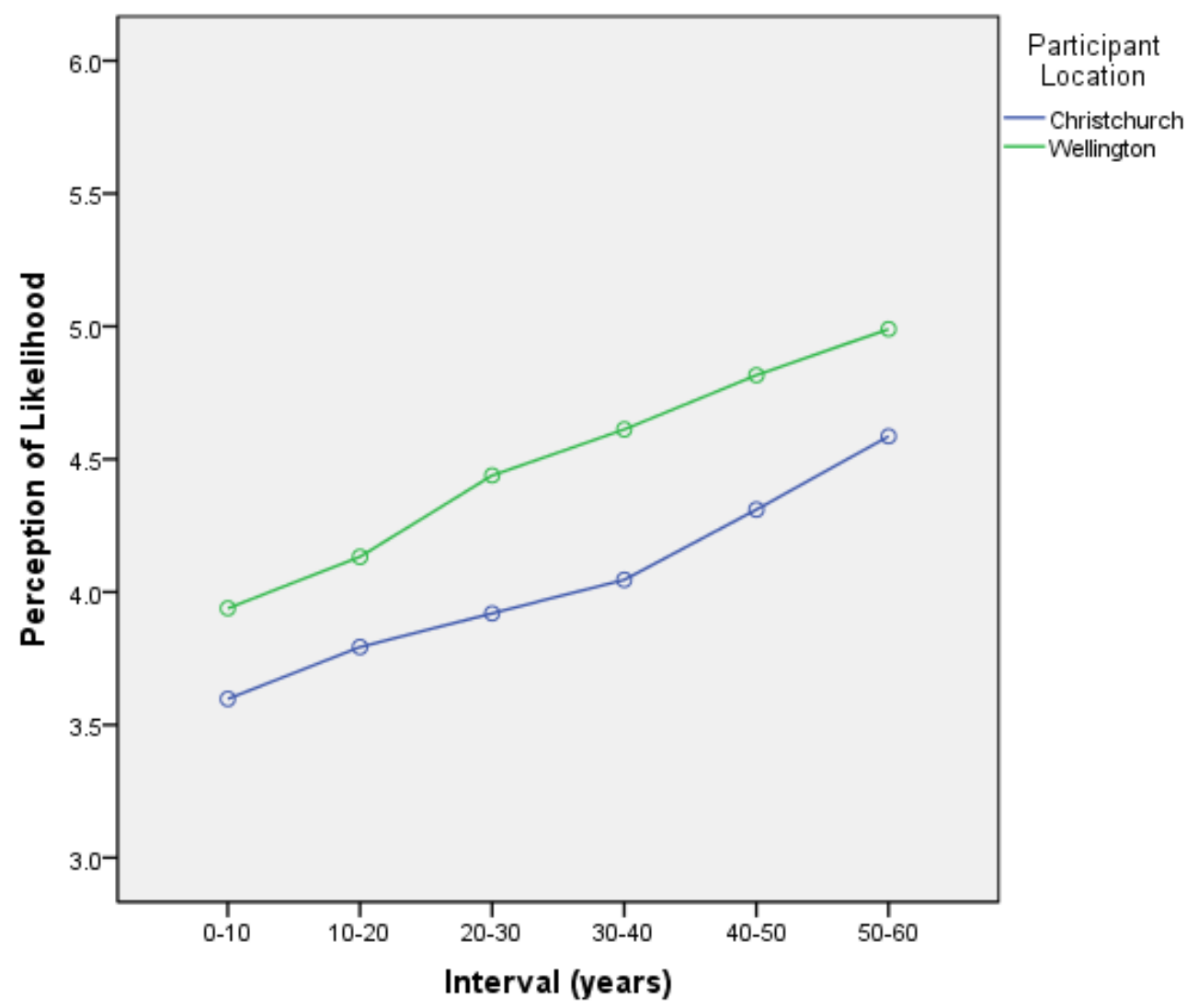

Analyses on demographic variables found a main effect for Participant location, showing that participants in Wellington rated earthquake likelihood higher $(\mathrm{M}=4.49)$ than participants in Christchurch $(M=4.04), F(1,182)=5.02, p<.05, \eta^{2}=.03$ (see Figure 2). There were three way interactions between Interval, Participant location and Age, $F(25,179)=1.76, p<.05, \eta^{2}=.07$, Participant location, Gender and Age, $F(4$, 179) $=2.72, p<.05, \eta^{2}=.08$, and Interval, Concern about the Wellington earthquake 
and Gender, $F(5,179)=3.89, p<.01, \eta^{2}=.04$. Further analysis to clarify these interactions revealed that females who were concerned about the Wellington earthquake risk rated their likelihood of making further preparations as higher in all intervals than those who were unconcerned. For males, those who were concerned about the Wellington earthquake statement rated their likelihood as slightly higher in later intervals, whereas those who were unconcerned rated their likelihood as much higher in the last interval $(M=5.10)$ than the first interval $(M=3.30)$. A main effect was found for Home ownership, $F(1,179)=4.88, p<.05, \eta^{2}=.04$, and a two way interaction was found between Participant location and Home ownership, $F(1,179)=4.31, p<.05, \eta^{2}=$ .03. No other significant effects were found.

\section{Likelihood of Increasing Preparedness for an Earthquake in Wellington}

Figure 3 shows the mean rating of likelihood of preparing more for an earthquake in Wellington for each of the six ten-year time intervals. A 2 (Participant location) x 6 (Interval) x 2 (Concerned about Wellington earthquake) x 2 (Home ownership) x 2 (Gender) x 6 (Age group) ANOVA was performed on the likelihood of preparing for a Wellington earthquake, with Interval a repeated measures variable and the other variables between subjects. In contrast to the earthquake likelihood data, there was no main effect for Interval, $F(5,181)=1.09$, ns. A main effect was found for Participant location, showing that participants in Wellington rated themselves as more likely to make further preparations $(M=5.40)$ than participants in Christchurch $(M=$ 4.72), $F(1,181)=8.30, p<.01, \eta^{2}=.05$ (see Figure 3 ). There was no two way interaction between likelihood of preparing more and Interval, $F(5,181)=0.19$, $n s$, and no significant effects for Gender or Concern about the earthquake risk in Wellington. 
Figure 3. Mean ratings of likelihood of preparing more for an earthquake in Wellington in each time interval.

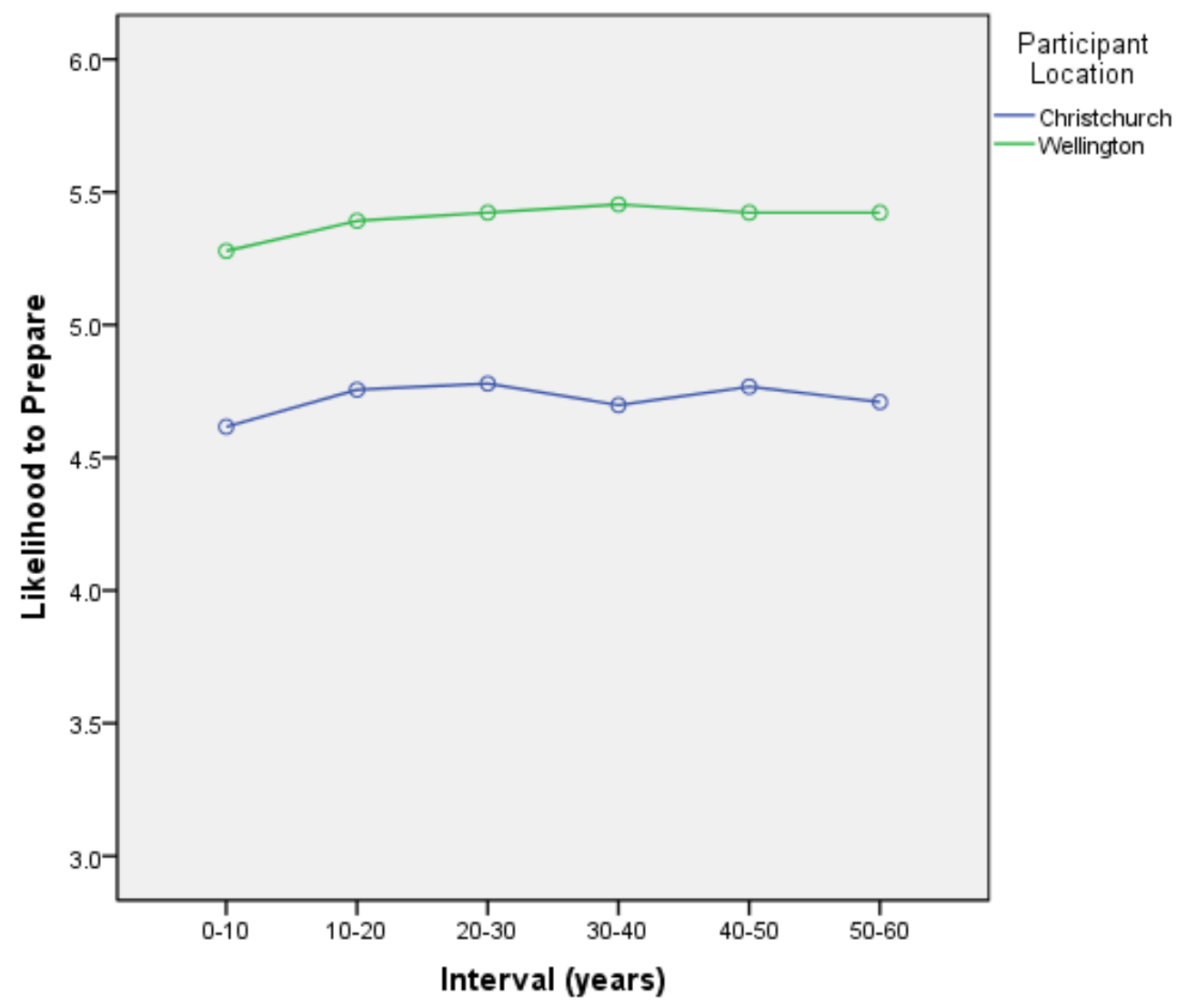

There was a two way interaction between Interval and Home ownership, $F(5$, $181)=2.63, p<.05, \eta^{2}=.02$. Further analysis showed that those who owned a home rated their likelihood of further preparing for a Wellington earthquake as higher than those who did not own a home. There were fluctuations but no specific trends across time windows to account for the interaction between Interval and Home ownership. A three way interaction was found between Interval, Home ownership and Gender, $F(5$, $181)=3.96, p<.01, \eta^{2}=.03$. Further analyses showed that males who owned a home rated their likelihood of making further preparations no differently to those who did not own a home in the first interval, whereas they rated their likelihood of making further 
preparations in the last interval higher $(M=5.17)$ than those who did not own a home $(M=4.41)$. In contrast, females who owned a home rated their likelihood of preparing more for an earthquake in Wellington no differently across the intervals, whereas those who did not own a home rated their likelihood of preparing more as higher in the last interval $(M=5.14)$ than the first interval $(M=4.85), t(52)=5.37, p<.001$.

Figure 4. Likelihood of preparing more for a Wellington earthquake, segmented by age group.

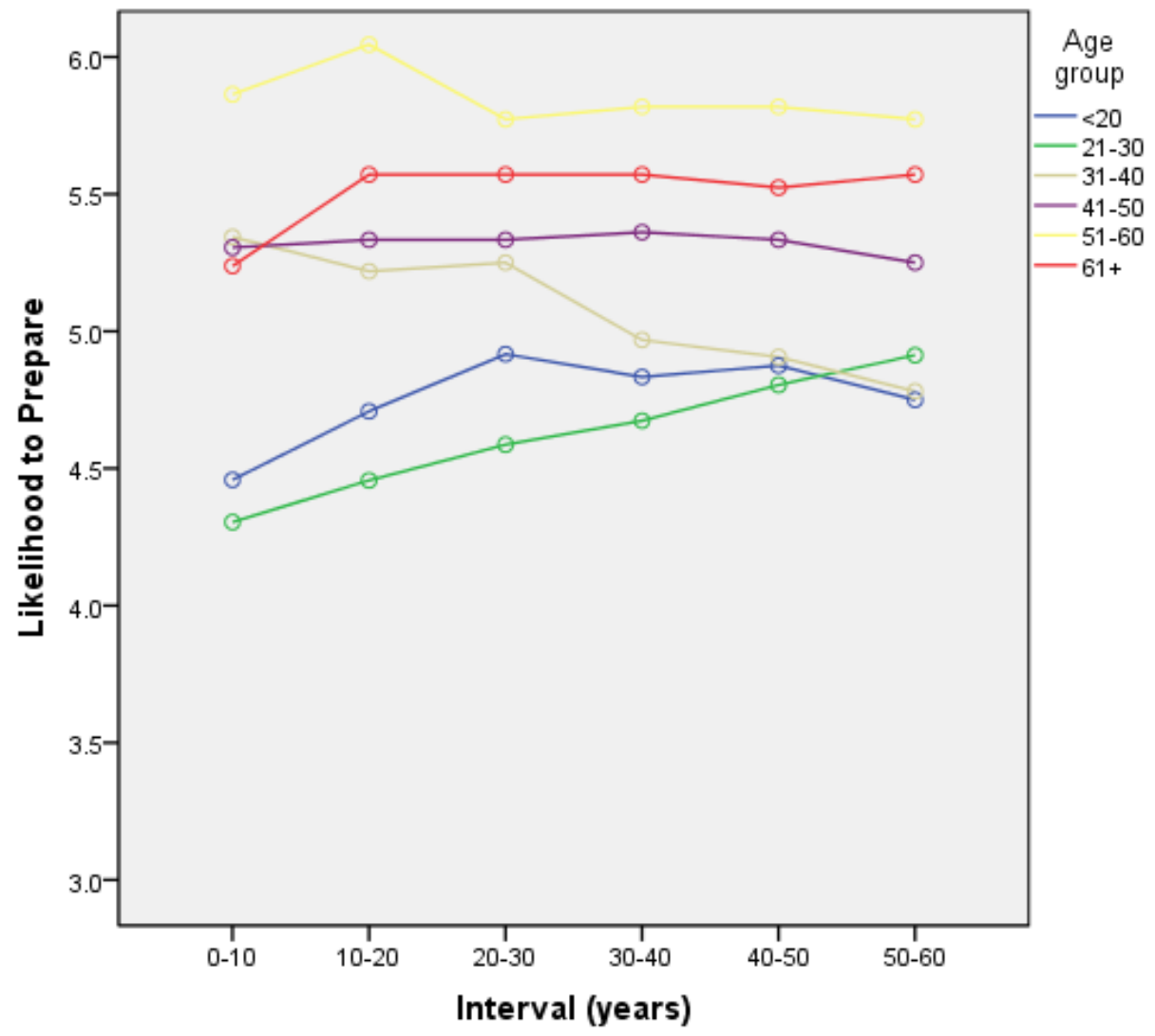

Figure 4 shows participants' likelihood of preparing further for a Wellington earthquake by Age group across the time window. A main effect was found for Age 
group, $F(5,181)=2.79, p<.05, \eta^{2}=.07$, with older Age groups more likely to prepare than younger Age groups.

\section{Judgements about an Aftershock in Christchurch}

Figure 5. Mean ratings of aftershock likelihood and preparation in Christchurch for each 2-month time interval in the time window.

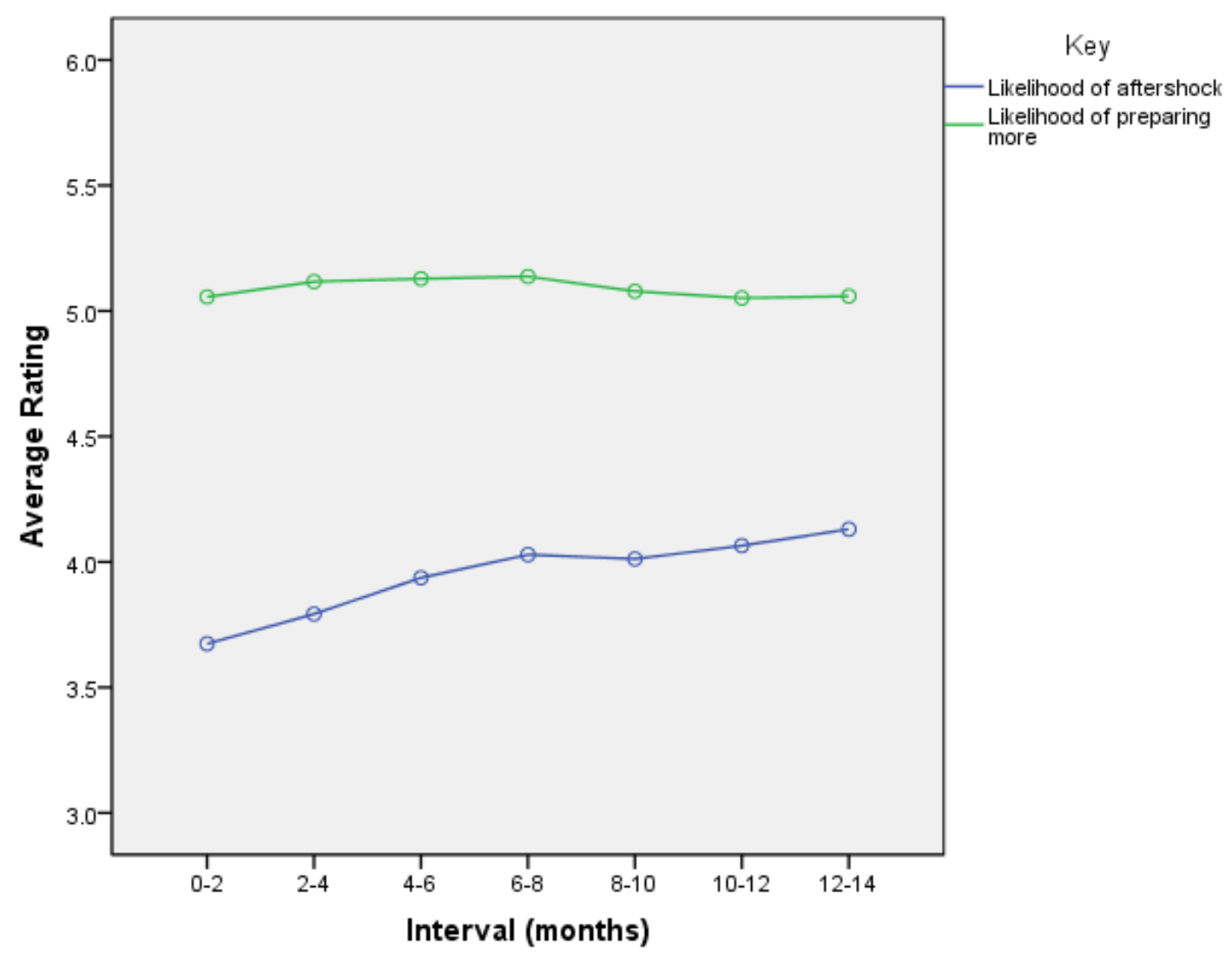

The mean rating of likelihood of an aftershock and likelihood of preparing more for the Christchurch aftershock is shown in Figure 5. A 2 (Measure: aftershock likelihood and preparation) x 6 (Interval) x 2 (Participant location) MANOVA was performed, with Participant location a between subjects variable and Measure and Interval repeated measures variables. As with the Wellington earthquakes data, a main 
effect was found for Measure, $F(1,183)=69.10, p<.001, \eta^{2}=.27$, showing that participants rated their likelihood of preparing more $(M=5.09)$ higher than they rated the likelihood of aftershocks occurring higher in later time intervals $(M=3.95$, see Figure 5). A main effect was also found for Interval, $F(6,178)=3.36, p<.01, \eta^{2}=.10$, showing that participants rated aftershock likelihood higher in later time intervals $(M=$ 4.60 in the last interval) than earlier intervals $(M=4.37$ in the first interval). A main effect was found for Participant location $F(1,183)=10.69, p<.01, \eta^{2}=.06$, showing that participants in Wellington rated likelihood higher $(M=4.83)$ than participants in Christchurch $(M=4.21)$. Interactions were found between Measure and Participant location, $F(1,183)=11.28, p<.01, \eta^{2}=.06$, and between Measure and Interval $F(6$, 178) $=2.22, p<.001, \eta^{2}=.07$, showing that the pattern across intervals was different for ratings of the likelihood of an aftershock (increasing across intervals) and the ratings of intention to prepare more (no significant difference across intervals). To clarify the interaction between Measure and Interval, separate analyses were subsequently performed on the aftershock likelihood and preparation data. There were no other significant effects.

\section{Perception of Aftershock Likelihood}

The mean rating of perception of likelihood of a significant aftershock in Christchurch in each of the two-month time intervals is shown in Figure 6. A 2 (Participant location) x 7 (Interval) x 2 (Concerned about Christchurch aftershock) x 2 (Home ownership) x 2 (Gender) x 6 (Age group) ANOVA was performed on ratings of the likelihood of aftershocks, with interval a repeated measures variable and the remainder being between subjects variables. A main effect was found for Interval, $F(6$, 
$183)=2.32, p<.05, \eta^{2}=.02$, showing that participants rated likelihood of an aftershock as higher in later intervals. Further analysis showed that for the first three intervals, ratings were significantly higher for subsequent intervals, all $p<.01$. In contrast, there was no significant difference between successive time intervals after the third interval, and ratings for intervals three and seven were not significantly different, $t(190)=1.60$, $n s$ (see Figure 6).

Figure 6. Mean ratings of perception of likelihood of an aftershock in Christchurch by time interval.

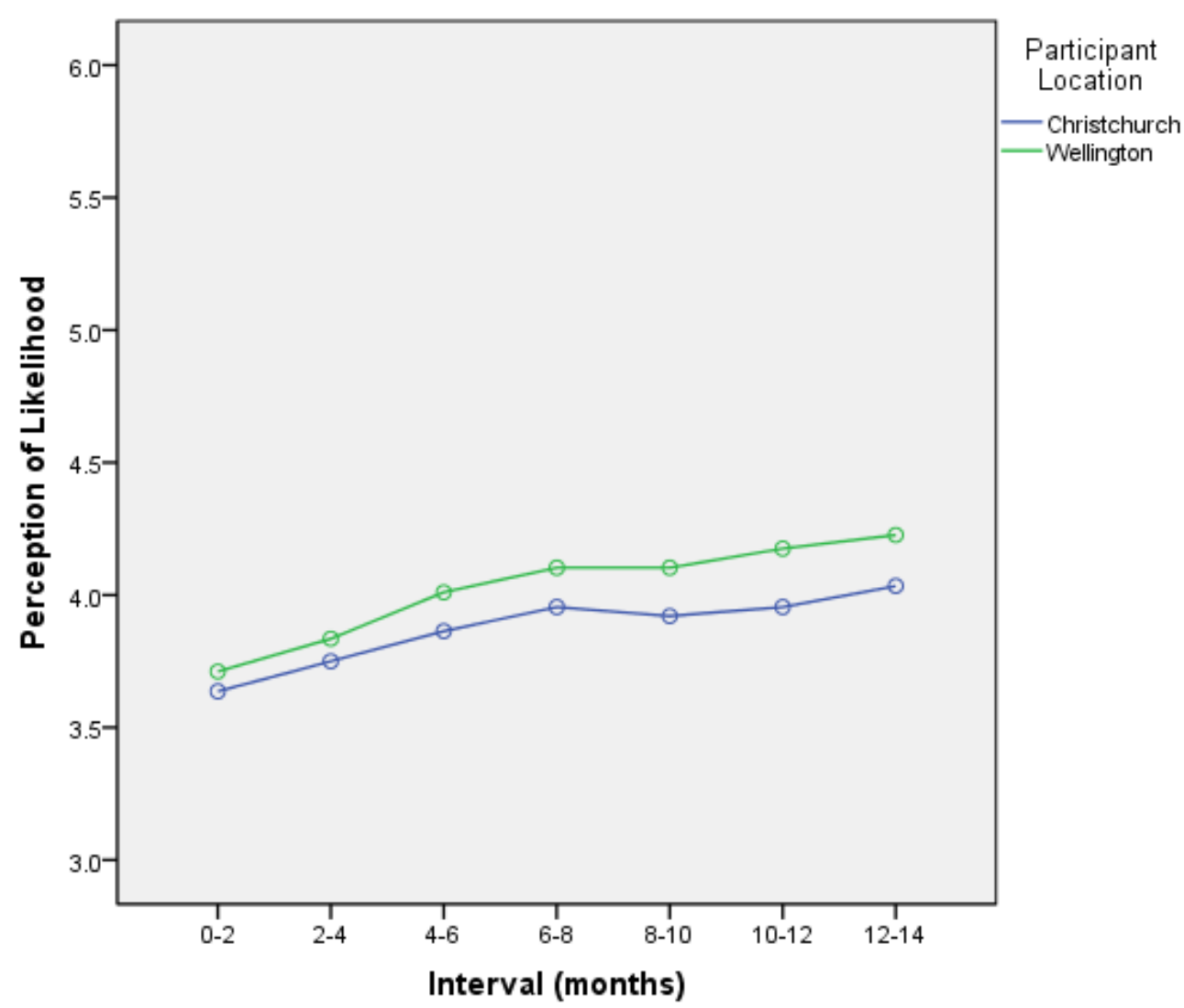

Analyses on demographic data showed a two way interaction between Participant location and Concern about the Christchurch aftershock, $F(1,183)=5.62, p$ 
$<.05, \eta^{2}=.04$, and between Home ownership and Age group, $F(5,183)=2.38, p<.05$, $\eta^{2}=.09$. There was no main effect for Participant location, $F(1,182)=0.50, n s$, and no interaction between Participant location and perception of likelihood of an aftershock, but there was a three way interaction between Interval, Participant location and Gender, $F(6,180)=2.36, p<.05$, and a four way interaction between Interval, Participant location, Gender and Concern about Christchurch aftershock, $F(6,183)=2.32, p<.05$, $\eta^{2}=.02$. To clarify the three way interaction, ratings from Christchurch and Wellington participants were separated, and a 2 (Gender) x 7 (Interval) ANOVA was performed on each. This showed that females in Wellington rated the likelihood of an aftershock in Christchurch as higher $(M=4.28)$ than males $(M=3.40), F(1,95)=9.16, p<.01$. In Christchurch, however, there was no main effect for Gender, $F(1,85)=1.71$, ns, but there was an interaction between Gender and Interval, $F(6,85)=3.67, p<.01$. Further analyses showed that males rated their likelihood of preparing more as lower in later intervals whereas females rated their likelihood of preparing more for a Christchurch aftershock as slightly higher in later intervals, however these differences were not significant $t(66)=1.72$, ns. There were also no significant effects for Home ownership or experience of the September, 2010 or February, 2011 Canterbury earthquakes.

\section{Likelihood of Increasing Preparedness for Aftershocks in Christchurch}

Figure 7 shows the mean rating of likelihood of preparing more for an aftershock in Christchurch for each of the seven two-month time intervals. A 2 (Participant location) x 7 (Interval) x 2 (Concerned about Christchurch aftershock) x 2 (Home ownership) x 2 (Gender) x 6 (Age group) ANOVA was performed, with Interval a repeated measures variable and the rest between subjects variables. An interaction was 
found between Participant location and Interval, $F(6,190)=2.13, p<.05, \eta^{2}=.01$. As shown in Figure 7, Wellington participants' rating of their likelihood of preparing more for a Christchurch aftershock in the first interval $(M=5.69)$, was higher than the rating for the last interval $(M=5.52)$. In contrast, for Christchurch participants the rating in the first interval $(M=4.44)$ was lower than the mean rating for the last interval $(M=$ 4.61).

Figure 7. Mean ratings of likelihood of preparing more for an aftershock in Christchurch by time interval.

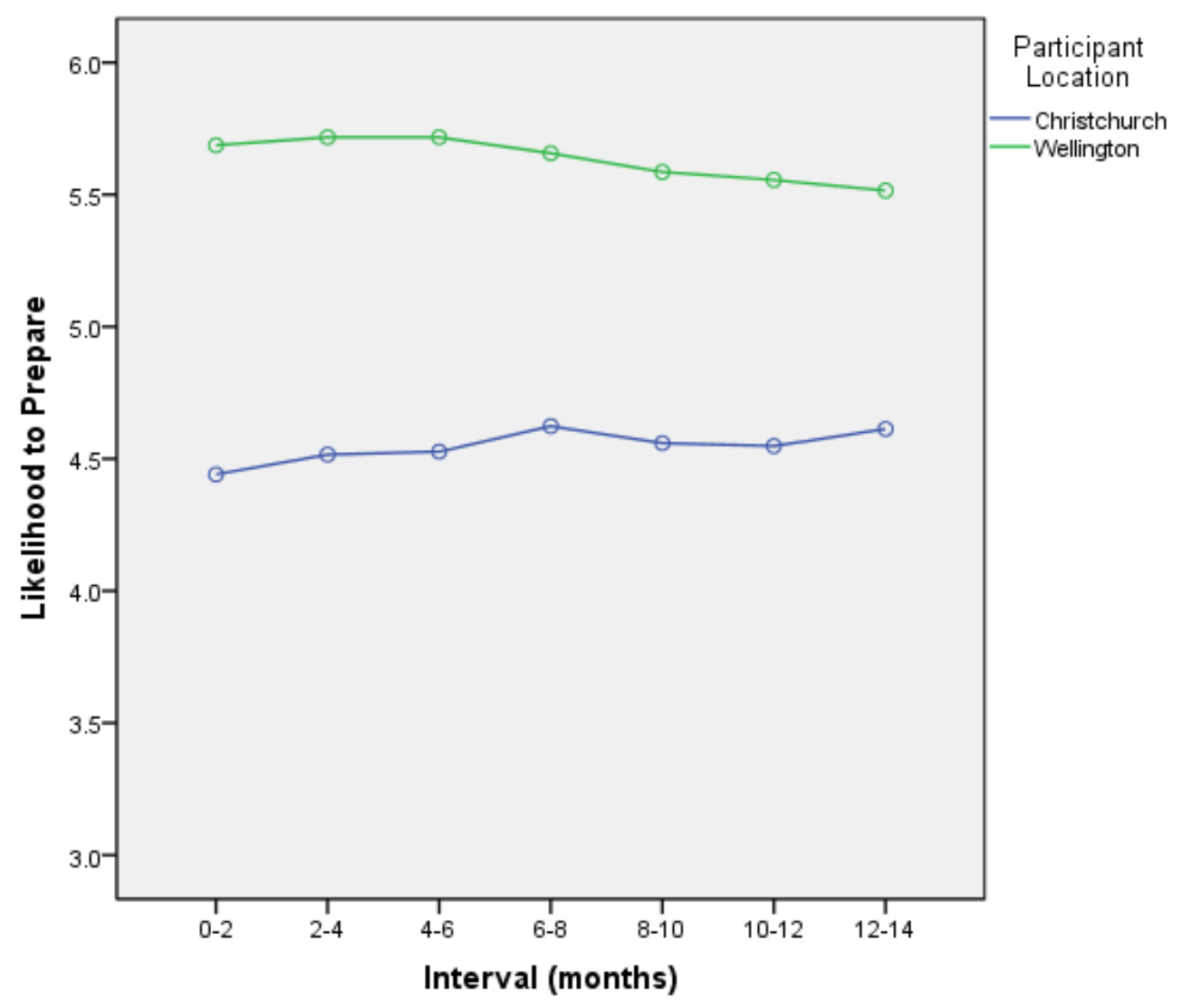


A main effect was found for Participant location, $F(1,190)=19.53, p<.001, \eta^{2}$ $=.06$, showing that participants in Wellington rated themselves as more likely to make further preparations for an aftershock in Christchurch $(M=5.63)$ than participants in Christchurch $(M=4.55)$. There was also a main effect for Gender, $F(1,190)=7.40, p<$ $.01, \eta^{2}=.06$, showing that females rated their intention to prepare more for an aftershock in Christchurch higher $(M=5.42)$ than males $(M=4.54)$. A main effect was found for Concern about risk, $F(1,185)=9.37, p<.01, \eta^{2}=.05$, indicating that those who were concerned by the scientist's estimate of Christchurch's aftershock risk rated their intention to prepare more for such an aftershock as higher $(M=5.32)$ than those unconcerned $(M=4.43)$. There were no significant interactions found. There were also no significant effects based on age group, home ownership or having experienced previous Canterbury earthquakes. There were no significant interactions.

\section{Current Preparedness and Likelihood of Preparing Further}

Figure 8 shows the ratings of likelihood of preparing more for a Wellington earthquake across the different ratings of current preparedness. Analyses were performed to explore the relationship between likelihood of preparing more and current ratings of preparedness. A 6 (Interval) x 7 (Preparedness) ANOVA was performed, and a main effect was found for Interval, $F(5,175)=2.26, p<.05, \eta^{2}=.01$. A main effect was also found for Preparedness, $F(6,175)=3.47, p<.01, \eta^{2}=.10$, showing that participants rating their current preparedness higher also rated their likelihood of preparing more in the future higher. No other significant effects were found. 
Figure 8. Likelihood of preparing more for a Wellington earthquake, segmented by current preparedness ratings.

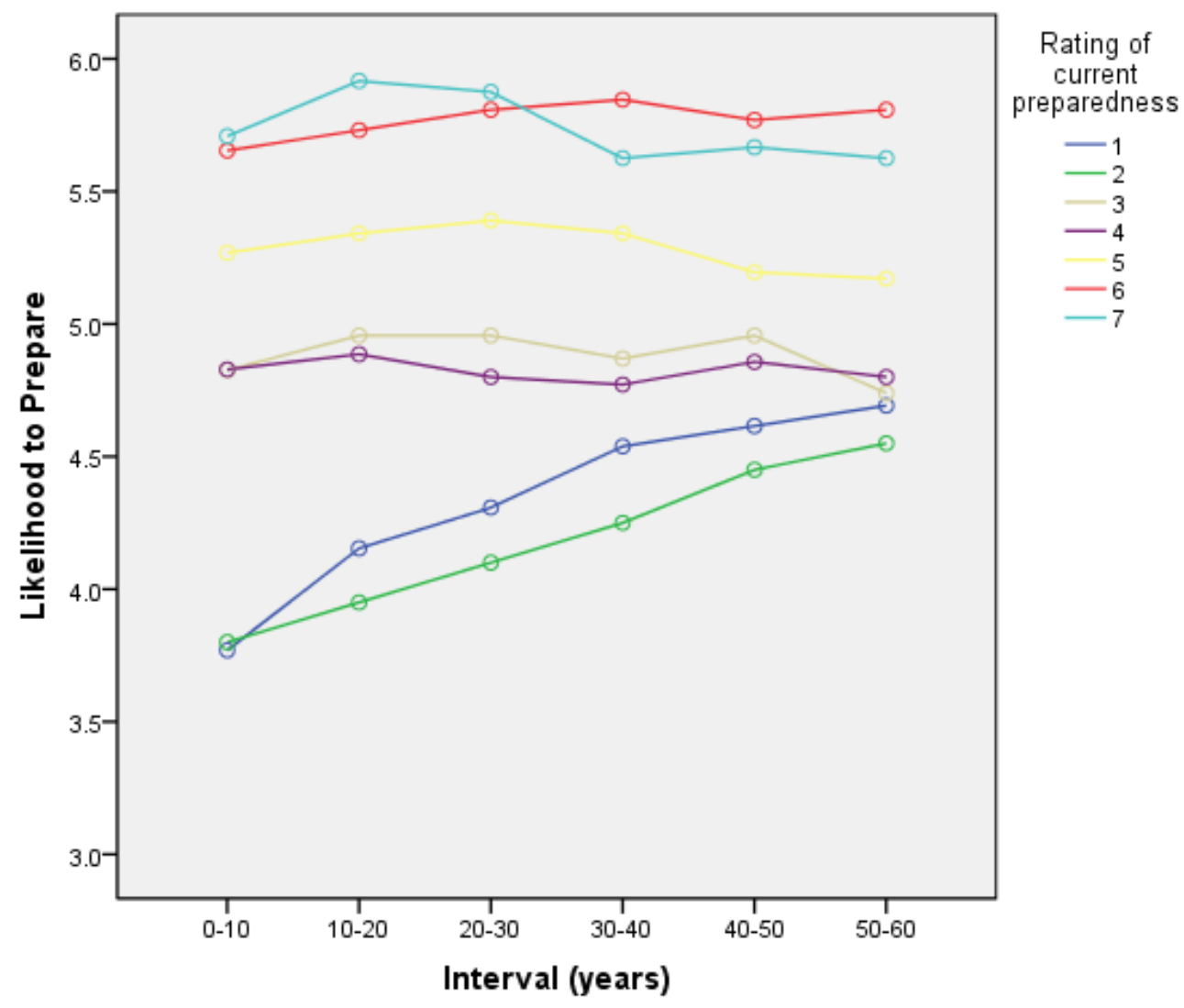

Figure 9 shows the ratings of likelihood of preparing more for a Christchurch aftershock across different ratings of current preparedness. A 7 (Interval) $x$ (Preparedness) ANOVA was performed. An interaction was found between Interval and Preparedness, $F(36,184)=1.83, p<.01, \eta^{2}=.07$, showing that those indicating a higher level of preparedness considered their likelihood of preparing more as relatively stable across the time window, while those with a lower level of current preparedness rated their likelihood of making further preparations differentially across the time window, in some cases dropping toward the end of the time window and in some cases increasing. No other significant effects were found. 
Figure 9. Likelihood of preparing more for a Christchurch aftershock, segmented by current preparedness ratings.

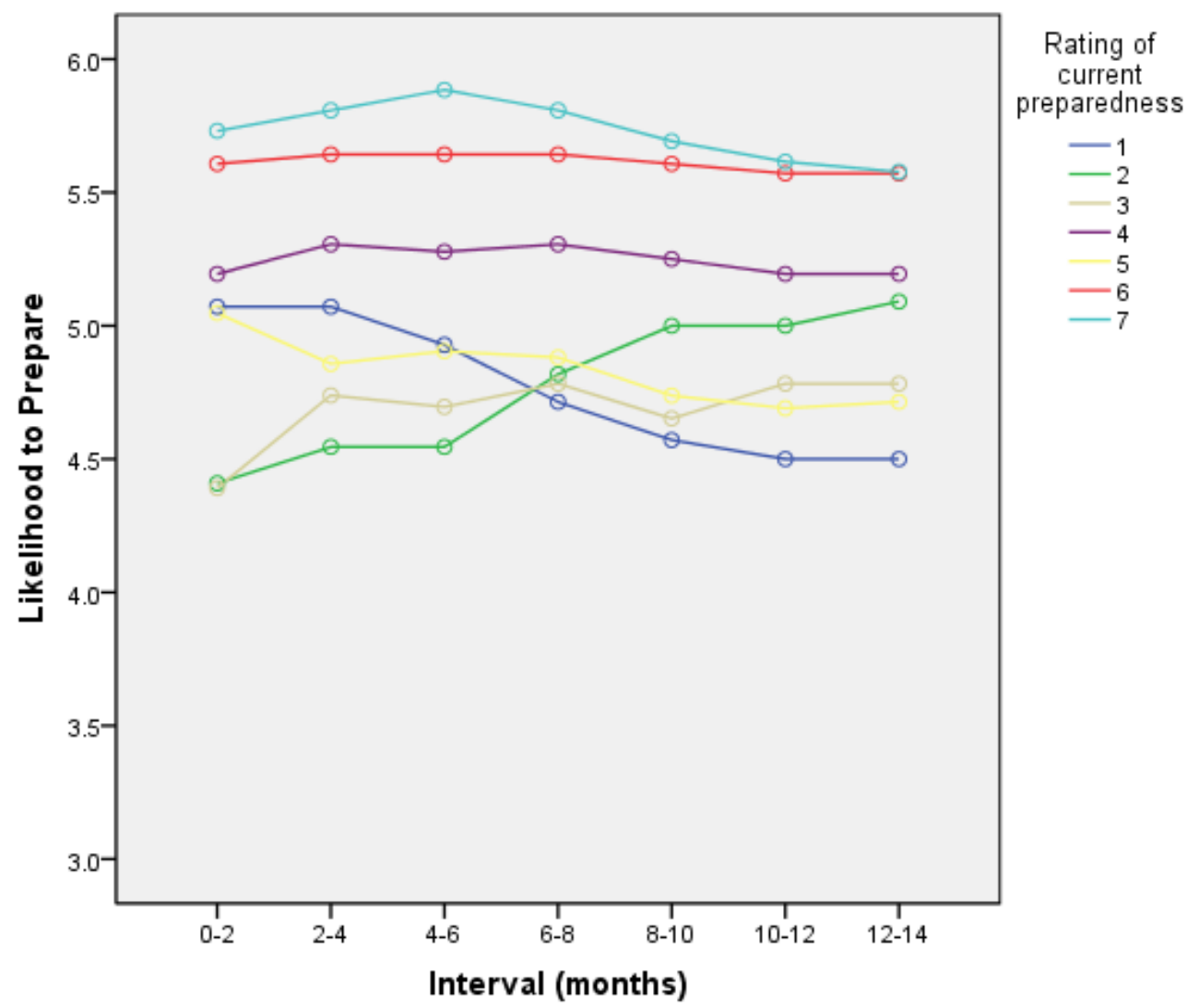

\section{Discussion}

Wellington and Christchurch provide two very different settings for seismic risk and public awareness of that risk. At the time of this study, earthquakes in Christchurch and surrounding areas have resulted in regular aftershocks for the region, while Wellington is known for its earthquake risk. The results show that people perceive earthquakes and aftershocks as more likely in later intervals within time windows in response to probability statements issued by scientists through the media, despite the absence of such statistical implication in those statements. As hypothesised, earthquake 
likelihood in Wellington was rated higher in later intervals in the time window. Also as hypothesised, ratings of the likelihood of an aftershock in Christchurch provided a different picture to Wellington earthquakes and to previous research (Doyle et al., 2012), with slightly higher ratings occurring across each of the first three intervals and remaining flat thereafter. However, this finding on the first three intervals with Christchurch aftershocks was in the opposite direction hypothesised, as predicted by base rate theory combined with the tendency of aftershocks towards decreasing over time.

The results also revealed differences in the way participants in Christchurch and Wellington view the likelihood of seismic events. Wellington participants rated an earthquake in Wellington as more likely than participants in Christchurch, despite being presented with the same information. They also rated their likelihood of preparing more for an earthquake in Wellington or an aftershock in Christchurch as higher than their Christchurch counterparts.

The findings for the Wellington earthquake data are consistent with those of Doyle et al. (2012), who examined the difference in judgements at different times within time windows in response to expert statements of volcanic eruption likelihood. The findings of the present study show the effect exists even more clearly for earthquakes over a 50 year time window than the three to five day, and ten year time windows examined by Doyle et al. (2012). 


\section{Judgements about an Earthquake in Wellington}

\section{Likelihood of an Earthquake Occurring}

Perceptions of the likelihood of a Wellington earthquake were as predicted. When presented with an expert assessment of earthquake likelihood over a time window, people rated the earthquake likelihood as higher in later parts of that window, despite a lack of statistical basis for this difference. Although residents of Wellington rated likelihood of an earthquake as higher than Christchurch residents, the same pattern existed for those in both cities. While ratings of the Wellington earthquake risk statement showed an upward trend over the time intervals, likelihood of preparing did not. Ratings of likelihood of preparing were no different across intervals. However, the inter-city difference remained similar as for perceived likelihood of an earthquake, with Wellington participants rating an earthquake in Wellington as more likely than Christchurch participants.

The overlaying of real world knowledge on expert statements of earthquake and aftershock risk provides a possible basis for understanding these findings. The statements presented to participants did not imply any difference in risk of an earthquake in different intervals in the time windows, and yet a very clear pattern emerged showing that likelihood was seen as greater in later intervals. This is consistent with the view that a combination of the expert statements and the overlay of a lay view of earthquake likelihood led to judgments of likelihood as increasing over time. Doyle et al. (2012) suggested that volcanoes are seen by citizens as building up in pressure over time and that this view accounts for people inferring higher likelihood of volcanic eruption in later intervals within time windows. This account may also apply to lay theories of earthquakes in Wellington, where scientists have published statements about 
earthquakes occurring on an approximate cycle of 600 years (Van Dissen et al., 2010). This type of statement suggests the inevitability of an earthquake, and may lead people to infer that the likelihood of an earthquake increases over time.

In contrast to previous research (Doyle et al., 2011; Doyle et al., 2012), this study found no decrease in likelihood ratings outside of the time period specified in the earthquake statements. On the basis of an earthquake risk statement for the next 50 years, participants rated the likelihood of an earthquake highest in the time window of 50 to 60 years, which was outside the expert statement's time window of 50 years. This finding may be a result of the difference in the dominant underlying theories of earthquakes and volcanoes. While a volcano may be seen as an event that may or may not occur, earthquakes may be seen as more inevitable. Thus, when given Doyle et al.'s (2012) scenario stating that a volcano was likely in the next five days, participants may view this as having two possible outcomes; either occurring or de-escalating within that period, whereas in the present study, the non-occurrence of an earthquake may be perceived as meaning the pressure has built up, making an earthquake only more likely after that time period.

\section{Likelihood of Increasing Preparedness for an Earthquake in Wellington}

Whereas the judgements of the likelihood of an earthquake in Wellington increased over time, it was hypothesised that this trend would not correspond with ratings of likelihood of preparing more across the time window. This hypothesis was not supported by the present study. Interestingly, there was no difference in participants' likelihood of preparing more for an earthquake in Wellington across the intervals for those in either Wellington or Christchurch. 
The findings revealed a difference between how people in Wellington and Christchurch view their likelihood of making further preparations for an earthquake in Wellington. Participants in Wellington rated their likelihood of preparing more for the Wellington earthquake described by the expert statement significantly higher than Christchurch participants. The questionnaire clearly stated that participants should assume they were going to live in Wellington for the whole time window and there was no indication (through comments on the questionnaire or verbal feedback) that this message was misunderstood. It is possible that having endured a significant number of earthquakes and aftershock events, people in Christchurch either consider themselves sufficiently prepared for future events, or exhibit fatalism about the efficacy of further preparations. The former reason was not supported by the findings relating to current preparedness and likelihood of preparing more, which revealed no significant difference in ratings of current preparedness between the two cities (discussed later). Further examination of current preparedness and likelihood of preparing would clarify this difference in likelihood of preparing more in the two cities found in the present study.

\section{Judgements about an Aftershock in Christchurch}

\section{Likelihood of an Aftershock Occurring}

The findings for judgements about the likelihood of Christchurch aftershocks show that these judgements are variable within a given time window. For the first three intervals spanning a six month period, ratings showed a slight upward trend for likelihood of a Christchurch aftershock for successive intervals. However, there was no difference between the remaining four intervals. I hypothesised that ratings of likelihood of an aftershock in Christchurch would decrease over time, which is the scientific 
expectation of aftershocks in Christchurch (GeoNet, 2013). However this prediction was not supported by the results, which showed that ratings of aftershock likelihood actually increased for the first three intervals and then plateaued for the remainder of the time window. This finding was the same for both Wellington and Christchurch participants.

The Christchurch aftershock picture is not as easily explained by the overlaying of real world knowledge as the Wellington earthquake results. It was hypothesised according to base rate theory that due to the decrease in likelihood of aftershocks over time predicted by experts, ratings of the likelihood of aftershocks would also decrease over time. Instead, the ratings of likelihood of the Christchurch aftershock described in the expert statement increased for the first three time windows. It is possible that due to the size of the aftershock described in the expert statement, the Christchurch aftershock was viewed as an earthquake in its own right, and therefore participants were overlaying their real world knowledge of the base rates of earthquakes rather than aftershocks. While aftershocks in general are viewed as decreasing in likelihood over time, the specific aftershock in the present study may have been viewed as an earthquake. Experts treat earthquakes and aftershocks as distinct events with different patterns in terms of likelihood over time, whereas the present findings show that lay people blur the distinction between the two.

A further consideration in the interaction between base rates and expert statements of risk is the severity of the risk statements (Weber \& Hilton, 1990). The Wellington earthquake described by the expert statement was more severe in magnitude than that describing the Christchurch aftershock. Wellington also has a large number of buildings and geographic areas with high earthquake risk, whereas since February, 
2011, when the second earthquake in the recent series of earthquakes occurred, Christchurch has had rigorous testing and demolition of high risk buildings. Further, participants' current level of preparedness may result in variations in perception of risk. For example, it may be expected that those living in Christchurch are more prepared for an aftershock having gone through so many earthquakes and aftershocks already. The combination of severity, current preparedness and base rate likelihood may all be significant in participant interpretation of, and judgements about, expert statements of earthquake and aftershock risk.

The results show an increase in ratings of likelihood across the first three time windows and the similar treatment of the aftershock and earthquake statements of risk by citizens in both Wellington and Christchurch. A possible reason for this is the fact that the aftershock in February, 2011 in Christchurch was a more damaging event than the original earthquake in September, 2010. Thus, perceptions of what an aftershock is, and the effects of an aftershock may have been affected by this experience, leading participants to treat the expert statement given in the present study as a statement of earthquake risk, rather than aftershock risk. This could be tested in the context of another earthquake with a more typical aftershock sequence. However, this finding is further evidence of the uniqueness of the Christchurch setting and psychological landscape at the time of the present study.

\section{Likelihood of Increasing Preparedness for an Aftershock in Christchurch}

As with the Wellington earthquake findings, the Christchurch aftershock likelihood ratings did not align with ratings of likelihood of preparing more for such an event. This was as hypothesised. However, higher ratings of likelihood of preparing 
more over the time window were related to gender (females rating themselves more likely than males to prepare more in all intervals), location (those in Wellington rating themselves more likely than those in Christchurch to prepare more in all intervals), and concern about Christchurch aftershocks (those who were concerned about the expert statement of risk rated themselves as more likely to make further preparations).

\section{Current Preparedness and Likelihood to Prepare Further}

The findings of this study also show that current preparedness is related to likelihood to make further preparations. This finding was shown for participants in both cities and for both a Wellington earthquake and Christchurch aftershock. Those who considered their current level of preparedness higher also rated their likelihood of preparing more higher than those with a lower current level of preparedness. Those who rated their current level of preparedness at the low end of the scale also appeared to show more variation in their likelihood to prepare more across the intervals. For Wellington earthquakes, those with the lowest current preparedness rated their likelihood of preparing more as higher at the end of the time window than the beginning. This could relate to the length of the time window (60 years) and the likelihood of owning a home and other significant assets across that time period, or it may suggest that those who are less prepared tend to procrastinate.

The present study shows that the relationship between perceptions of likelihood of an event and people's ratings of their likelihood to prepare is somewhat complex. An increased perception of the likelihood of an earthquake or aftershock does not correspond to an increased likelihood of preparing more at later time intervals. Several factors may be relevant to this difference. Firstly, ratings of likelihood of preparing 
more and actually preparing more are separate measures. Ratings of preparation likelihood are similar to intentions, and the intention to prepare does not always lead to preparation actions (Mulilis \& Duval, 1995; Paton, 2003). This study asked participants about their likelihood of preparing more, which was necessary due to the time periods presented being in the future. It would be informative to follow up on participants over time to see how well future actions mirror present expectations. Secondly, it is possible that participants believed themselves adequately prepared. This may be particularly relevant to Christchurch participants who have already survived several major earthquakes and many significant aftershocks. However, a lack of consistency between perceived likelihood of an earthquake and ratings of likelihood of preparing more is consistent with previous research (McClure et al., 1999; Spittal et al., 2008).

\section{Demographic Factors in Likelihood of Preparation}

The findings for demographic factors provide further evidence for the different picture of the two cities included in the present research. Participants in Wellington rated the likelihood of an earthquake in Wellington as higher than those in Christchurch, and females in Wellington rated the likelihood of a Christchurch aftershock as higher than males. There are several possible causes of these findings. Heller, Alexander, Gatz, Knight, and Rose (2005) suggested that those who have experienced an earthquake but sustained no harm may be inclined to prepare less, and that preparedness may be more related to experience of damage or loss in an earthquake than simply having experienced an earthquake. This may relate to the inclination to also discount the risk of such an event, as the present study has found. The findings may also point to the psychological factors outlined by Heller et al. (2005) of neuroticism and worry, or more 
positively framed, conscientiousness. Such an account would suggest that both females and Wellington citizens are more conscientious about earthquake risk in New Zealand than Christchurch citizens.

Previous research has considered the link between home ownership, gender and previous experience of earthquakes and preparedness. The findings of the present study showed that these factors work together in non-trivial ways. Consistent with previous research (e.g., McClure et al., 1999; Spittal et al., 2008), home owners in Wellington rated their likelihood of making further preparations for a Wellington earthquake as higher than those who did not own a home. Males who owned a home indicated the same level of present likelihood to prepare more (in the first interval) than those who did not, but a greater likelihood to prepare more in the last interval. This finding may suggest that homeowners showed more procrastination than non-homeowners. Alternatively, it may suggest that non-homeowners exhibit apathy whereas homeowners have intentions to prepare more. The opposite effect was found for females, with those owning a home indicating no difference in likelihood to prepare across the intervals, and non-homeowners indicating a higher likelihood of making further preparations later in the time window.

In contrast, participants in Christchurch with previous experience showed no difference in likelihood to prepare for future aftershocks or earthquakes. Also, those who owned a home did not indicate a greater or lesser likelihood to make further preparations. This is contrary to the suggestion of Heller et al. (2005) that those who have experienced previous earthquakes without suffering damage or loss may be more fatalistic and less likely to prepare. However, the present study differed from that of Heller et al. (2005) in that ratings were of likelihood to prepare more, not actual 
preparation, and the experience measure did not differentiate between those who had suffered damage or loss and those who had not.

The finding of a main effect for age was consistent with previous research (e.g., Sattler, Kaiser, \& Hittner, 2000). Younger participants rated their likelihood to make further preparations lower than older participants. This finding may have been even clearer for both Christchurch aftershocks and Wellington earthquakes if the present study had used fewer, wider age groups (e.g., three 30 year age groups).

\section{Limitations of the Present Research and Future Directions}

The findings of this study show a clear picture of perceptions in Wellington and Christchurch of both earthquakes and aftershocks. However, due to the different intervals presented for earthquakes and aftershocks it is difficult to compare the two. Seven two-month intervals were presented for a 14 month time window for a Christchurch aftershock, whereas the Wellington earthquake statement used a 60 year time window and six 10-year intervals. A variation of design allowing the direct comparison of intervals in Christchurch and Wellington would help to clarify why the results were less clear in Christchurch, and how judgements about earthquakes and aftershocks differ. For example, this could be achieved by excluding actual lengths from time window information, such as "Experts state there is a $90 \%$ chance of a magnitude 7.0 or greater earthquake in the next $\mathrm{N}$ years", and specifying fractions rather than set time frames for the intervals, such as "The first quarter", "The second quarter", "The third quarter" and "The last quarter" of the time window.

A second difference that the present study did not examine was the difference in magnitude and probability of the two events. The Christchurch aftershock probability 
was stated at $33 \%$, whereas the Wellington earthquake probability was $90 \%$. These are at different places on the binary weighting scale (Patt \& Schrag, 2003), and therefore may account in part for the view of earthquakes in the present study as inevitable, and aftershocks less so. Further, the magnitude and by extension, the severity of the two events was considerably different. The Christchurch aftershock statement asked citizens to consider a 5.5 magnitude (on the Richter scale) event, compared with the Wellington earthquake statement which stated a 7.0 magnitude event. Having suffered a number of greater than 5.5 events already, such an aftershock would likely be far lower in severity for Christchurch than a significantly larger 7.0 earthquake in Wellington. Severity is known to have an effect on perception of likelihood (Weber \& Hilton, 1990). Therefore these factors make the comparison of the Christchurch aftershock and Wellington earthquake mentioned previously even more desirable.

The present study also used only self-reports for all measures. For current preparedness and likelihood of preparing more this may have resulted in participants answering these questions differently. It would be interesting to combine self-reports with other, more objective measures of current preparedness to see how these relate. However, for the present study perceptions of current preparedness are potentially more relevant to perceptions of likelihood of preparing more than actual preparedness.

\section{Conclusion}

The findings of this study show that the effects on the tendency to elevate risk in later time intervals found by Doyle et al. (2011) also apply to earthquakes and to a lesser extent to aftershocks. This is a significant finding given the difference in time periods applied to common reports about earthquakes compared with those for 
volcanoes. Previous research presented time windows of five day (Doyle et al., 2011) and ten year (Doyle et al., 2012) lengths, as applicable to volcanic eruptions, whereas the present study presented periods more applicable to earthquakes and aftershocks -50 years and 12 months respectively. The findings of higher event likelihood of this study, especially those for likelihood of earthquakes, are even clearer than those found for volcanoes in the previous research. When presented scientific statements of earthquake and aftershock risk in time windows, as reported in mass media, people perceive that risk as higher in later intervals within the given time window.

The overlaying of real world knowledge and base rate theory can account for the findings of this study, but further research is required to better understand the actual base rates and real world knowledge that people hold about earthquakes and aftershocks to better confirm and disentangle these links. 


\section{References}

Bar-Hillel, M. (1980). The base-rate fallacy in probability judgments. Acta Psychologica, 44(3), 211-233. doi: http://dx.doi.org/10.1016/0001$\underline{6918(80) 90046-3}$

Cowan, J., McClure, J., \& Wilson, M. (2002). What a difference a year makes: How immediate and anniversary media reports influence judgements about earthquakes. [Article]. Asian Journal Of Social Psychology, 5(3), 169-185.

Davey, R., \& Shephard, R. (1995). Earthquake risk assessment study: study area 1, Wellington City: Works Consultancy Serivces.

Dhami, M. K., \& Wallsten, T. S. (2005). Interpersonal comparison of subjective probabilities: Toward translating linguistic probabilities. Memory \& Cognition (pre-2011), 33(6), 1057-1068. doi: 10.1016/0001-6918(93)e0071910.1016/0001-6918(93)e0071-91996-07575-001

Doyle, E. H., Johnston, D. M., McClure, J., \& Paton, D. (2011). The Communication of Uncertain Scientific Advice During Natural Hazard Events. The New Zealand Journal of Psychology, 40(4), 11.

Doyle, E. H., McClure, J., Johnston, D. M., \& Paton, D. (2012). The shifting of likelihood perceptions for time window.

GeoNet. (2013). Aftershocks Retrieved May, 2012, from http://info.geonet.org.nz/display/home/Aftershocks

Heller, K., Alexander, D. B., Gatz, M., Knight, B. G., \& Rose, T. (2005). Social and Personal Factors as Predictors of Earthquake Preparation: The Role of Support Provision, Network Discussion, Negative Affect, Age, and Education1. Journal of Applied Social Psychology, 35(2), 399-422.

Kahneman, D., \& Tversky, A. (1979). Prospect Theory: An Analysis of Decision under Risk. Econometrica, 47(2), 263-291. doi: 10.2307/1914185 
Karelitz, T. M., \& Budescu, D. V. (2004). You Say "Probable" and I Say "Likely": Improving Interpersonal Communication With Verbal Probability Phrases. Journal of Experimental Psychology: Applied, 10(1), 25-41.

Lindell, M. K., \& Perry, R. W. (2000). Household adjustment to earthquake hazard a review of research. Environment and Behavior, 32(4), 461-501.

Lindell, M. K., \& Whitney, D. J. (2000). Correlates of household seismic hazard adjustment adoption. Risk Analysis, 20(1), 13-26.

McClure, J., Allen, M., \& Walkey, F. (2001). Countering Fatalism: Causal Information in News Reports Affects Judgments About Earthquake Damage. Basic and Applied Social Psychology, 23(2), 109-121. doi: 10.1207/s15324834basp2302_3

McClure, J., Sutton, R. M., \& Sibley, C. G. (2007). Listening to Reporters or Engineers? How Instance-Based Messages About Building Design Affect Earthquake Fatalism. Journal of Applied Social Psychology, 37(9), 17.

McClure, J., Walkey, F., \& Allen, M. (1999). When earthquake damage is seen as preventable: Attributions. Locus of control, and attitudes to risk. Applied Psychology: An International Review, 48, 239-256.

McClure, J., \& Williams, S. (1996). Community preparedness: Countering helplessness and optimism. Psychological aspects of disaster: Impact, coping, and prevention, 237-254.

McClure, J., Wills, C., Johnston, D., \& Recker, C. (2011). How the 2010 Canterbury (Darfield) earthquake affected earthquake risk perception: Comparing citizens inside and outside the earthquake region. Australasian Journal of Disaster and Trauma Studies, 2011, 2.

Mulilis, J.-P., \& Duval, T. S. (1995). Negative threat appeals and earthquake preparedness: A person-relative-to-event $(\mathrm{PrE})$ model of coping with threat. Journal of Applied Social Psychology, 25(15), 1319-1339. 
Paton, D. (2003). Disaster preparedness: A social-cognitive perspective. Disaster Prevention and Management, 12(3), 6.

Patt, A. G., \& Schrag, D. P. (2003). Using specific language to describe risk and probability. Climatic Change, 61(1-2), 17-30.

Piotrowski, C., \& Armstrong, T. R. (1998). MASS MEDIA PREFERENCE IN DISASTER: A STUDY OF HURRICANE DANNY. [Article]. Social Behavior \& Personality: An International Journal, 26(4), 341.

Pollatsek, A., Well, A. D., Konold, C., Hardiman, P., \& Cobb, G. (1987). Understanding conditional probabilities. Organizational Behavior and Human Decision Processes, 40(2), 255-269. doi: http://dx.doi.org/10.1016/0749$\underline{5978(87) 90015-X}$

Russell, L. A., Goltz, J. D., \& Bourque, L. B. (1995). Preparedness and Hazard Mitigation Actions before and after Two Earthquakes. Environment and Behavior, 27(6), 744-770. doi: 10.1177/0013916595276002

Rüstemli, A., \& Karanci, A. N. (1999). Correlates of earthquake cognitions and preparedness behavior in a victimized population. The Journal of Social Psychology, 139(1), 91-101.

Sattler, D. N., Kaiser, C. F., \& Hittner, J. B. (2000). Disaster Preparedness: Relationships Among Prior Experience, Personal Characteristics, and Distress1. Journal of Applied Social Psychology, 30(7), 1396-1420.

Seligman, M. E. P. (1972). Learned Helplessness. Annual Review of Medicine, 23(1), 407-412. doi: doi:10.1146/annurev.me.23.020172.002203

Smith, K. (1993). Environmental Hazards: Assessing Risk and Reducing Disaster. Routledge, London.

Spittal, M. J., McClure, J., Siegert, R. J., \& Walkey, F. H. (2008). Predictors of Two Types of Earthquake Preparation Survival Activities and Mitigation Activities. Environment and Behavior, 40(6), 798-817. 
Steel, P. (2007). The nature of procrastination: a meta-analytic and theoretical review of quintessential self-regulatory failure. Psychological bulletin, 133(1), 65.

Strickland, B. R. (1989). Internal€xternal control expectancies: From contingency to creativity. American Psychologist, 44(1), 1-12.

Turner, R. H., Nigg, J. M., \& Heller Paz, D. (1986). Waiting for disaster. London: University of California Press.

Van Dissen, R., Barnes, P., Beavan, J., Cousins, J., Dellow, G., Francois-Holden, C., . . . Little, T. (2010). It's Our Fault: better defining earthquake risk in Wellington.

Vasterman, P., Yzermans, C. J., \& Dirkzwager, A. J. (2005). The role of the media and media hypes in the aftermath of disasters. [Review]. Epidemiologic Reviews, 27, 107-114. doi: 10.1093/epirev/mxi002

Wallsten, T. S., Fillenbaum, S., \& Cox, J. A. (1986). Base rate effects on the interpretations of probability and frequency expressions. Journal of Memory and Language, 25(5), 571-587. doi: http://dx.doi.org/10.1016/0749-596X(86)90012$\underline{4}$

Walters, L. M., \& Hornig, S. (1993). Faces in the news: Network television news coverage of Hurricane Hugo and the Loma Prieta. [Article]. Journal of Broadcasting \& Electronic Media, 37(2).

Weber, E. U. (1994). From subjective probabilities to decision weights: The effect of asymmetric loss functions on the evaluation of uncertain outcomes and events. Psychological bulletin, 115(2), 228-242. doi: 10.1016/0749-5978(92)90024210.1016/0749-5978(92)90024-21993-00298-001

10.1037/0022-3514.63.4.534144768410.1037/0022-3514.63.4.5341993-04316-001

Weber, E. U., \& Hilton, D. J. (1990). Contextual effects in the interpretations of probability words: Perceived base rate and severity of events. Journal of Experimental Psychology: Human Perception and Performance, 16(4), 781-789. 
Windschitl, P. D., \& Weber, E. U. (1999). The interpretation of "likely" depends on the context, but "70\%" is 70\%-right? The influence of associative processes on perceived certainty. Journal of Experimental Psychology: Learning, Memory, and Cognition, 25(6), 1514-1533. 
Appendix A: Questionnaires 
Order 1:

\section{Christchurch Aftershocks}

Consider the following scenario: Leading NZ scientists state that the likelihood of a 5.5 5.9 magnitude aftershock in Christchurch is 33\% in the next 12 months.

1. Does this concern you? $\quad \mathrm{Y} / \mathrm{N}$

2. Please indicate your perception of the likelihood of such an aftershock occurring in Christchurch within each of the following two-month time windows. If you are unsure, please put your best guess (circle one):

\begin{tabular}{|c|c|c|c|c|c|c|c|}
\hline \multirow{2}{*}{ Time Window } & \multicolumn{7}{|c|}{ Likelihood } \\
\hline & $\begin{array}{l}\text { Extremely } \\
\text { unlikely }\end{array}$ & & & & & & $\begin{array}{l}\text { Virtually } \\
\text { certain }\end{array}$ \\
\hline In the next two months & 1 & 2 & 3 & 4 & 5 & 6 & 7 \\
\hline In two to four months & 1 & 2 & 3 & 4 & 5 & 6 & 7 \\
\hline In four to six months & 1 & 2 & 3 & 4 & 5 & 6 & 7 \\
\hline In six to eight months & 1 & 2 & 3 & 4 & 5 & 6 & 7 \\
\hline In eight to ten months & 1 & 2 & 3 & 4 & 5 & 6 & 7 \\
\hline In ten to twelve months & 1 & 2 & 3 & 4 & 5 & 6 & 7 \\
\hline In twelve to fourteen months & 1 & 2 & 3 & 4 & 5 & 6 & 7 \\
\hline
\end{tabular}

3. Any comments?

4. Assuming you were going to live in Christchurch for the next 14 months, please indicate how likely you are to prepare more for such an aftershock in Christchurch in each of the following two-month time windows:

\begin{tabular}{|c|c|c|c|c|c|c|c|}
\hline \multirow{2}{*}{ Time Window } & \multicolumn{7}{|c|}{ Likelihood } \\
\hline & $\begin{array}{c}\text { Extremely } \\
\text { unlikely }\end{array}$ & & & & & & $\begin{array}{c}\text { Virtually } \\
\text { certain }\end{array}$ \\
\hline In the next two months & 1 & 2 & 3 & 4 & 5 & 6 & 7 \\
\hline In two to four months & 1 & 2 & 3 & 4 & 5 & 6 & 7 \\
\hline In four to six months & 1 & 2 & 3 & 4 & 5 & 6 & 7 \\
\hline In six to eight months & 1 & 2 & 3 & 4 & 5 & 6 & 7 \\
\hline In eight to ten months & 1 & 2 & 3 & 4 & 5 & 6 & 7 \\
\hline In ten to twelve months & 1 & 2 & 3 & 4 & 5 & 6 & 7 \\
\hline In twelve to fourteen months & 1 & 2 & 3 & 4 & 5 & 6 & 7 \\
\hline
\end{tabular}

5. Any comments? 


\section{Wellington Earthquake}

Consider the following scenario: Leading NZ scientists state that the likelihood of a magnitude 7 earthquake occurring within $100 \mathrm{~km}$ of Wellington is $90 \%$ in the next 50 years.

1. Does this concern you? $\quad \mathrm{Y} / \mathrm{N}$

2. Please indicate your perception of the likelihood of such an earthquake in Wellington within each of the following ten-year time windows. If you are unsure, please put your best guess (circle one):

\begin{tabular}{|l|l|l|l|l|l|l|l|}
\hline \multirow{2}{*}{ Time Window } & \multicolumn{3}{c|}{ Likelihood } & $\begin{array}{c}\text { Virtually } \\
\text { certain }\end{array}$ \\
\cline { 2 - 8 } & $\begin{array}{c}\text { Extremely } \\
\text { unlikely }\end{array}$ & & & & 7 \\
\hline In the next ten years & 1 & 2 & 3 & 4 & 5 & 6 & 7 \\
\hline In ten to twenty years & 1 & 2 & 3 & 4 & 5 & 6 & 7 \\
\hline In twenty to thirty years & 1 & 2 & 3 & 4 & 5 & 6 & 7 \\
\hline In thirty to forty years & 1 & 2 & 3 & 4 & 5 & 6 & 7 \\
\hline In forty to fifty years & 1 & 2 & 3 & 4 & 5 & 6 & 7 \\
\hline In fifty to sixty years & 1 & 2 & 3 & 4 & 5 & 6 & 7 \\
\hline
\end{tabular}

\section{Any comments?}

4. Assuming you were going to live in Wellington for the next 60 years, please indicate how likely you would be to prepare more for such an earthquake in Wellington in each of the following ten-year time windows.

\begin{tabular}{|l|l|l|l|l|l|l|l|}
\hline \multicolumn{2}{|c|}{} & \multicolumn{3}{c|}{ Likelihood } & $\begin{array}{c}\text { Virtually } \\
\text { certain }\end{array}$ \\
\cline { 2 - 9 } & $\begin{array}{c}\text { Extremely } \\
\text { unlikely }\end{array}$ & & & & & 7 \\
\hline In the next ten years & 1 & 2 & 3 & 4 & 5 & 6 & 7 \\
\hline In ten to twenty years & 1 & 2 & 3 & 4 & 5 & 6 & 7 \\
\hline In twenty to thirty years & 1 & 2 & 3 & 4 & 5 & 6 & 7 \\
\hline In thirty to forty years & 1 & 2 & 3 & 4 & 5 & 6 & 7 \\
\hline In forty to fifty years & 1 & 2 & 3 & 4 & 5 & 6 & 7 \\
\hline In fifty to sixty years & 1 & 2 & 3 & 4 & 5 & 6 & 7 \\
\hline
\end{tabular}

\section{Any comments?}

\section{How prepared do you feel you are now for an earthquake?}

1

Extremely

unprepared
2

3

4

5

7

Extremely prepared
7. Do you own a house?
$\mathrm{Y} / \mathrm{N}$
8. Gender:
$\mathrm{M} / \mathrm{F}$
Suburb:
9. Age:
$<20 \quad 21-30 \quad 31-40$
$41-50 \quad 51-60$
$61+$

10. Were you in Christchurch during the September or February earthquake? $Y / N$ 
Order 2:

\section{Wellington Earthquake}

Consider the following scenario: Leading NZ scientists state that the likelihood of a magnitude 7 earthquake occurring within $100 \mathrm{~km}$ of Wellington is $90 \%$ in the next 50 years.

1. Does this concern you? $\quad \mathrm{Y} / \mathrm{N}$

2. Please indicate your perception of the likelihood of such an earthquake in Wellington within each of the following ten-year time windows. If you are unsure, please put your best guess (circle one):

\begin{tabular}{|l|l|l|l|l|l|l|l|}
\hline \multirow{2}{*}{ Time Window } & \multicolumn{3}{c|}{ Likelihood } & $\begin{array}{c}\text { Virtually } \\
\text { certain }\end{array}$ \\
\cline { 2 - 8 } & $\begin{array}{c}\text { Extremely } \\
\text { unlikely }\end{array}$ & & & & & 7 \\
\hline In the next ten years & 1 & 2 & 3 & 4 & 5 & 6 & 7 \\
\hline In ten to twenty years & 1 & 2 & 3 & 4 & 5 & 6 & 7 \\
\hline In twenty to thirty years & 1 & 2 & 3 & 4 & 5 & 6 & 7 \\
\hline In thirty to forty years & 1 & 2 & 3 & 4 & 5 & 6 & 7 \\
\hline In forty to fifty years & 1 & 2 & 3 & 4 & 5 & 6 & 7 \\
\hline In fifty to sixty years & 1 & 2 & 3 & 4 & 5 & 6 & 7 \\
\hline
\end{tabular}

3. Any comments?

4. Assuming you were going to live in Wellington for the next $\mathbf{6 0}$ years, please indicate how likely you would be to prepare more for such an earthquake in Wellington in each of the following ten-year time windows.

\begin{tabular}{|c|c|c|c|c|c|c|c|}
\hline \multirow{2}{*}{ Time Window } & \multicolumn{7}{|l|}{ Likelihood } \\
\hline & $\begin{array}{c}\text { Extremely } \\
\text { unlikely }\end{array}$ & & & & & & $\begin{array}{c}\text { Virtually } \\
\text { certain }\end{array}$ \\
\hline In the next ten years & 1 & 2 & 3 & 4 & 5 & 6 & 7 \\
\hline In ten to twenty years & 1 & 2 & 3 & 4 & 5 & 6 & 7 \\
\hline In twenty to thirty years & 1 & 2 & 3 & 4 & 5 & 6 & 7 \\
\hline In thirty to forty years & 1 & 2 & 3 & 4 & 5 & 6 & 7 \\
\hline In forty to fifty years & 1 & 2 & 3 & 4 & 5 & 6 & 7 \\
\hline In fifty to sixty years & 1 & 2 & 3 & 4 & 5 & 6 & 7 \\
\hline
\end{tabular}

\section{Any comments?}




\section{Christchurch Aftershocks}

Consider the following scenario: Leading NZ scientists state that the likelihood of a 5.5 5.9 magnitude aftershock in Christchurch is $33 \%$ in the next 12 months.

1. Does this concern you? $\quad \mathrm{Y} / \mathrm{N}$

2. Please indicate your perception of the likelihood of such an aftershock occurring in Christchurch within each of the following two-month time windows. If you are unsure, please put your best guess (circle one):

\begin{tabular}{|c|c|c|c|c|c|c|c|}
\hline \multirow{2}{*}{ Time Window } & \multicolumn{7}{|c|}{ Likelihood } \\
\hline & $\begin{array}{c}\text { Extremely } \\
\text { unlikely }\end{array}$ & & & & & & $\begin{array}{l}\text { Virtually } \\
\text { certain }\end{array}$ \\
\hline In the next two months & 1 & 2 & 3 & 4 & 5 & 6 & 7 \\
\hline In two to four months & 1 & 2 & 3 & 4 & 5 & 6 & 7 \\
\hline In four to six months & 1 & 2 & 3 & 4 & 5 & 6 & 7 \\
\hline In six to eight months & 1 & 2 & 3 & 4 & 5 & 6 & 7 \\
\hline In eight to ten months & 1 & 2 & 3 & 4 & 5 & 6 & 7 \\
\hline In ten to twelve months & 1 & 2 & 3 & 4 & 5 & 6 & 7 \\
\hline In twelve to fourteen months & 1 & 2 & 3 & 4 & 5 & 6 & 7 \\
\hline
\end{tabular}

\section{Any comments?}

4. Assuming you were going to live in Christchurch for the next 14 months, please indicate how likely you are to prepare more for such an aftershock in Christchurch in each of the following two-month time windows:

\begin{tabular}{|c|c|c|c|c|c|c|c|}
\hline \multirow{2}{*}{ Time Window } & \multicolumn{7}{|c|}{ Likelihood } \\
\hline & $\begin{array}{c}\text { Extremely } \\
\text { unlikely }\end{array}$ & & & & & & $\begin{array}{c}\text { Virtually } \\
\text { certain }\end{array}$ \\
\hline In the next two months & 1 & 2 & 3 & 4 & 5 & 6 & 7 \\
\hline In two to four months & 1 & 2 & 3 & 4 & 5 & 6 & 7 \\
\hline In four to six months & 1 & 2 & 3 & 4 & 5 & 6 & 7 \\
\hline In six to eight months & 1 & 2 & 3 & 4 & 5 & 6 & 7 \\
\hline In eight to ten months & 1 & 2 & 3 & 4 & 5 & 6 & 7 \\
\hline In ten to twelve months & 1 & 2 & 3 & 4 & 5 & 6 & 7 \\
\hline In twelve to fourteen months & 1 & 2 & 3 & 4 & 5 & 6 & 7 \\
\hline
\end{tabular}

5. Any comments?

6. How prepared do you feel you are now for an earthquake?

1

Extremely

unprepared
3

2

7. Do you own a house?

8. Gender:

9. Age:
4

$\mathrm{Y} / \mathrm{N}$

$\mathrm{M} / \mathrm{F}$

$<20 \quad 21-30 \quad 31-40$
5

6

6
7

Extremely prepared

10.Were you in Christchurch during the September or February earthquake? Y / N 